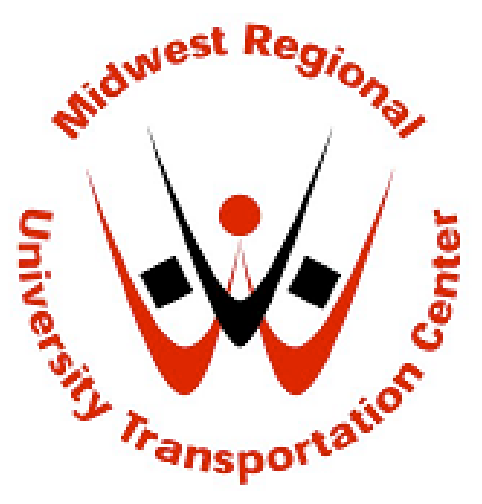

SYSTEM MANAGEMENT AND MONITORING - TEMPORAL EVALUATION OF FREEWAY MANAGEMENT SYSTEMS

Project 04-02

February 2005

Midwest Regional University Transportation Center College of Engineering Department of Civil and Environmental Engineering University of Wisconsin, Madison

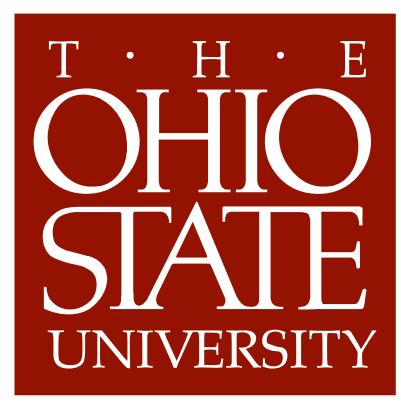

Principal Investigators and Authors:

Benjamin Coifman, Assistant Professor ab; Keith Redmill, Senior Research Associate b; Carolyn Merry, Professor a

a Department of Civil and Environmental Engineering and Geodetic Science, The Ohio State University, http://www.ceegs.ohio-state.edu

${ }^{b}$ Department of Electrical and Computer Engineering, The Ohio State University, http://www.ece.osu.edu 


\section{EXHIBIT B}

Technical Report Documentation Page

\begin{tabular}{|c|c|c|c|}
\hline $\begin{array}{l}\text { 1. Report No. } \\
\text { MRUTC 04-02 }\end{array}$ & 2. Government Accession No. & \multicolumn{2}{|c|}{$\begin{array}{l}\text { 3. Recipient's Catalog No. } \\
\text { CFDA 20.701 }\end{array}$} \\
\hline \multirow{2}{*}{\multicolumn{2}{|c|}{$\begin{array}{l}\text { 4. Title and Subtitle } \\
\text { System Management and Monitoring - Temporal Evaluation of Freeway Management Systems }\end{array}$}} & \multicolumn{2}{|c|}{ 5. Report Date May 30, 2005} \\
\hline & & \multicolumn{2}{|c|}{ 6. Performing Organization Code } \\
\hline \multicolumn{2}{|l|}{$\begin{array}{l}\text { 7. Author/s } \\
\text { Coifman, B., Redmill, K., Merry, C. }\end{array}$} & \multicolumn{2}{|c|}{$\begin{array}{l}\text { 8. Performing Organization Report No. } \\
\text { MRUTC 04-02 }\end{array}$} \\
\hline \multirow{2}{*}{\multicolumn{2}{|c|}{$\begin{array}{l}\text { 9. Performing Organization Name and Address } \\
\text { Midwest Regional University Transportation Center } \\
\text { University of Wisconsin-Madison } \\
\mathbf{1 4 1 5} \text { Engineering Drive, Madison, WI } 53706\end{array}$}} & \multicolumn{2}{|c|}{ 10. Work Unit No. (TRAIS) } \\
\hline & & \multicolumn{2}{|c|}{$\begin{array}{l}\text { 11. Contract or Grant No. } \\
\text { DTRS 99-G-0005 }\end{array}$} \\
\hline \multirow{2}{*}{\multicolumn{2}{|c|}{$\begin{array}{l}\text { 12. Sponsoring Organization Name and Address } \\
\qquad \begin{array}{l}\text { U.S. Department of Transportation } \\
\text { Research and Special Programs Administration } \\
4007^{\text {th }} \text { Street, SW } \\
\text { Washington, DC 20590-0001 }\end{array}\end{array}$}} & \multicolumn{2}{|c|}{$\begin{array}{l}\text { 13. Type of Report and Period Covered } \\
\text { Final Report }[\mathbf{3 / 1 / 0 4}-\mathbf{3 / 3 1 / 0 5}]\end{array}$} \\
\hline & & \multicolumn{2}{|c|}{ 14. Sponsoring Agency Code } \\
\hline \multicolumn{4}{|c|}{$\begin{array}{l}\text { 15. Supplementary Notes } \\
\text { Project completed for the Midwest Regional University Transportation Center with support from the Wisconsin Department of } \\
\text { Transportation. }\end{array}$} \\
\hline \multicolumn{4}{|l|}{$\begin{array}{l}\text { 16. Abstract } \\
\text { Virtually every major metropolitan area i } \\
\text { of accidents, decrease the time required to } \\
\text { are myopic, focusing strictly on current co } \\
\text { over time. The goal of this study is to inve } \\
\text { to show the added benefit of the given syst } \\
\text { Metropolitan Freeway Management Syste }\end{array}$} \\
\hline $\begin{array}{l}\text { 17. Key Words } \\
\text { Freeways } \\
\text { Traffic monitoring }\end{array}$ & $\begin{array}{l}\text { 18. Distribution Statement } \\
\text { No restrictions. This report is available } \\
\text { Information Services of the National Tra }\end{array}$ & $\begin{array}{l}\text { the Transportation } \\
\text { ion Library. }\end{array}$ & Research \\
\hline $\begin{array}{l}\text { 19. Security Classification (of this report) } \\
\text { Unclassified }\end{array}$ & $\begin{array}{l}\text { 20. Security Classification (of this page) } \\
\text { Unclassified }\end{array}$ & $\begin{array}{l}\text { 21. No. Of Pages } \\
35\end{array}$ & $\begin{array}{l}\text { 22. Price } \\
\mathbf{- 0 -}\end{array}$ \\
\hline
\end{tabular}

Form DOT F 1700.7 (8-72)

Reproduction of form and completed page is authorized. 


\title{
SYSTEM MANAGEMENT AND MONITORING - TEMPORAL EVALUATION OF FREEWAY MANAGEMENT SYSTEMS
}

\author{
Midwest Regional University Transportation Center
}

Assistant Professor Benjamin A. Coifman

$\begin{array}{ll}\text { Department of Civil Engineering } & \text { v: (614) 292-4282 } \\ \text { The Ohio State University } & \text { f: (614) 292-3780 } \\ 470 \text { Hitchcock Hall } & \text { e: coifman.1@osu.edu } \\ \text { Columbus, OH } 43210 & \text { w: http://eewww.eng.ohio-state.edu/ coifman }\end{array}$

Senior Research Associate Keith A. Redmill

$\begin{array}{ll}\text { Department of Electrical Engineering } & \text { v: (614) } 292-5216 \\ \text { The Ohio State University } & \text { f: (614) 292-7596 } \\ \text { 205 Dreese Laboratory } & \text { e: redmill@ee.eng.ohio-state.edu } \\ \text { Columbus, OH 43210 } & \text { w: http://www.eleceng.ohio-state.edu/ redmill/ }\end{array}$

Professor Carolyn J. Merry

Department of Civil Engineering v: (614) 292-6889

The Ohio State University f: (614) 292-3780

470 Hitchcock Hall e: merry.1@osu.edu

Columbus, $\mathrm{OH} 43210 \quad$ w: http://www.ceegs.ohio-state.edu/ merry/

\section{Disclaimer}

This research was funded by the Midwest Regional University Transportation Center through the Transportation Asset Management Pooled Fund Research Program administered by the Wisconsin Department of Transportation and the Federal Highway Administration. The contents of this report reflect the views of the authors, who are responsible for the facts and the accuracy of the information presented herein. This document is disseminated under the sponsorship of the Department of Transportation, University Transportation Centers Program, in the interest of information exchange. The U.S. Government assumes no liability for the contents or use thereof. The contents do not necessarily reflect the official views of the Midwest Regional University Transportation Center, the University of Wisconsin, the Wisconsin Department of Transportation or the Federal Highway Administration at the time of publication.

The United States Government assumes no liability for its contents or use thereof. This report does not constitute a standard, specification, or regulation.

The United States Government does not endorse products or manufacturers. Trade and manufacturers' names appear in this report only because they are considered essential to the object of the document. 


\section{INTRODUCTION}

Virtually every major metropolitan area in the US has a traffic monitoring system to help increase traffic throughput, decrease the number of accidents, decrease the time required to clear incidents that disrupt flow, and provide travelers information. Almost all of these systems are myopic, focusing strictly on current conditions. Yet the data collected by the sensors can provide considerable information when viewed over time. The goal of this study is to investigate and demonstrate several applications that employ traffic monitoring system data over time to show the added benefit of the given system. Many of these tools have been demonstrated in real time using data from the Columbus Metropolitan Freeway Management System (CMFMS), the intelligent freeway management system in the greater Columbus, Ohio area.

\section{Background}

The Ohio Department of Transportation (ODOT), in conjunction with the city of Columbus and the Federal Highway Administration, has deployed the first phase of the CMFMS. Figure 1 shows a schematic of the currently deployed system along I-70 and I-71, covering roughly 14 miles of freeway with detector stations every third of a mile (dual loop detector stations every mile, spanned by two single loop detector stations in between), ramp meters, 4 changeable message signs (CMS), and an integrated traffic management center (TMC) to coordinate different government agencies and the media. The system became operational at the end of 2001.

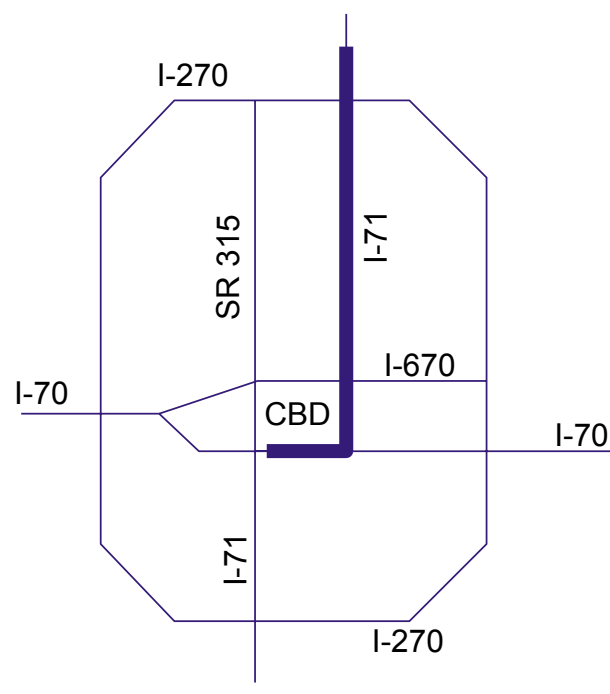

reeways in Columbus, Ohio

Currently instrumented portion of the CMFMS

Figure 1, Map of the freeway system in Columbus, $\mathrm{OH}$ showing the 14 miles of instrumented facility stretching north from the central business district 
Researchers from the Traffic Monitoring Laboratory at the Ohio State University are undertaking a research study for ODOT to evaluate the performance of the CMFMS. Data for this evaluation are being collected on the mainline and ramps using the CMFMS loop detectors, dedicated probe vehicle runs and Central Ohio Transit Agency (COTA) automatic vehicle location (AVL) system on transit vehicles in the corridor. This study provides quantitative and qualitative results such as: travel times, speed data, traffic volume, and traveler delay. The study also develops a suite of performance monitoring tools both to assess the performance of instrumented freeways and the reliability of the surveillance system.

We have developed a system to present various performance measures to help several classes of users - travelers, practitioners, and researchers. To this end we use data from the CMFMS to illustrate many of the features in real-time. Underlying this research is the necessary data fusion from the various sources. It is argued that such an extension helps optimize the investment in traffic monitoring systems by integrating historical trends over time, with various benefits such as the potential to reduce peak demands on the system while educating the wide range of users. In short, analysis as developed in this research will help optimize operations through better management of the system. Such a system can educate the public, helping them make better transportation decisions and avoid congested periods. It also provides a comprehensive overview of the given traffic monitoring system for practitioners, allowing them to optimize the system. In the course of this work we integrated information from many sources to meet multiple objectives for system management and monitoring.

\section{Research Objectives}

The research sought to develop performance measures from traffic monitoring systems and provide the information to three classes of users - the traveling public, practitioners and researchers - to help manage the roadway assets more effectively. As discussed below, we have collected data from numerous sources, including loop detector data from ODOT, transit vehicle AVL data from COTA, and probe vehicle data from our own dedicated runs. The first task of the research was developing the necessary data fusion tools to merge these diverse data sources, exploit the specific strengths of a given source, and address any discrepancies between conflicting data sources.

The second task was the production and provision of meaningful information for travelers. Our work goes further than simply presenting current conditions on a real time speed map, several of the tools are specifically designed to educate travelers and help them plan their travel to avoid congestion. Drivers are generally motivated to reduce the time necessary to travel but lack knowledge about their alternatives. We addressed this gap in part by providing historical travel times throughout the entire day, thereby allowing drivers to plan their day and avoid heavily congested periods. Such a tool will help reduce peaks in demand and improve infrastructure utilization.

In the third task we produce tools to extract data useful to practitioners, employing the same philosophy behind the Freeway Performance Measurement System (PeMS) [1]. The presentation includes conventional measurements such as average daily travel (ADT), vehicle miles traveled (VMT), and detector status; but the work also implements new metrics, such as delay as a function of time and space. Most of the figures presented in this report were manually 
generated off-line, however, we have demonstrated the capability to generate these plots on the fly for practitioners and allow them to manipulate the contents [2]. Finally, to ensure accurate data, we have developed and deployed data validation tools - automated diagnostics to identify when detectors are not providing accurate data, e.g., [3-4].

\section{Related Work}

Washington State Department of Transportation (WSDOT) provides a clear and concise traffic speed map, as well as numerous web cameras for users to view current conditions [5]. The majority of the cameras only provide still images, though some provide video clips. The web page also offers information on incidents and current estimated travel times. The web page also offers numerous links to related information, both across the state and via other modes such as rail. There are numerous examples of real time traffic data maps offering various degrees of the real time data similar to the WSDOT page, e.g., the Gary-Chicago-Milwaukee corridor [6], Milwaukee, WI [7], San Francisco, Bay Area, [8], Houston, TX [9], Phoenix, AZ [10], Toronto, ON [11], and Portland, OR [12]. In fact most major US cities have traffic maps and there are even several commercial companies that offer traffic data, often in conjunction with the local operating agencies, e.g., $[13,14]$. There are even more examples of pages providing a subset of such data, e.g., the Columbus, Ohio traffic cameras $[15,16]$.

Most of the on-line traveler information pages are devoted entirely to real time information, discounting the value of historical data. Presumably this omission is due in part to the difficulty in communicating how to interpret the data. There are a few notable exceptions that do attempt to leverage historical data, WSDOT offers a planning tool that helps travelers estimate the typical travel time on various routes for specific departure times [17], while Houston provides plots of average trip speed for specific origin destination pairs as a function of time of day, [18, 19].

But the omission of historical information is also due to the fact that many practitioners fail to recognize the value. There are several on-going efforts to mine the vast quantities of data collected by real time traffic monitoring systems. The Freeway Performance Measurement System (PeMS) is probably the most comprehensive of such systems, offering summary reports to operators, raw data to researchers, and historical trends to users [1]. There are several other systems that provide similar mining tools, e.g., ADMS Virginia [20], Traffic Data Acquisition and Distribution at the University of Washington [21], and the Portland Transportation Archive Listing [22]. Each one of these systems is local in terms of the data, covering at most an entire state. But the analysis tools can easily be transferred to any traffic monitoring system (or conversely, data from other cities could be presented in the data mining tools). Of course some accommodation may be necessary in the event of different data formats, e.g., one traffic monitoring system provides lane-by-lane data while another only provides data averaged across all lanes. 


\section{DATA SourCes}

This research employs data from numerous sources. The primary source is the detectors in the CMFMS, as discussed momentarily. The research also includes data from dedicated, GPS equipped probe vehicle runs and COTA AVL GPS data in the corridor.

Before aggregation at the TMC the loop detectors provide transition data to OSU, which is not only valuable to basic research but also allows for more precise data cleaning. To illustrate this point, consider the hypothetical example shown in Figure 2. This example shows the detector response to two passenger cars, one truck, and one detector error in the absence of a vehicle.

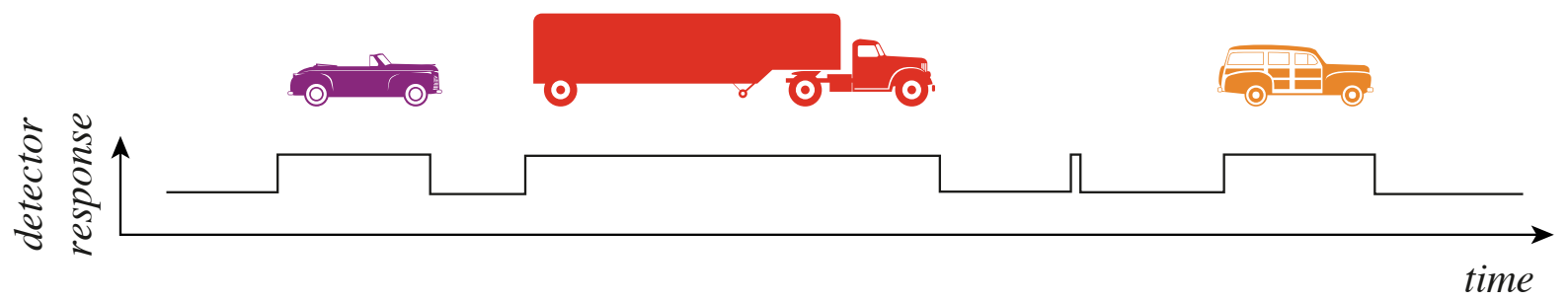

Figure 2, A hypothetical example showing the detector response to three successive vehicles and one erroneous-detection.

Unless they are frequent, errors such as the short on-time due to the erroneous actuation go unnoticed in conventional aggregated data but are often easy to identify in the transition data. At the other extreme, many trucks have an effective length that is four times that of the median effective vehicle length. As shown in [23], this variance in length can cause significant errors in conventional speed estimates from single loop detectors, i.e.,

$$
\text { mean }(\text { speed })=\frac{\hat{L} \cdot q}{\text { occupancy }}=\frac{\hat{L}}{\text { mean }(\text { on }- \text { time })}
$$

where $\hat{L}$ is the assumed average vehicle length. But as shown in Figure 2, the long vehicles can extend the mean on-time and thus reduce the estimated speed even though traffic is not actually moving slower. To reduce susceptibility to unusually long vehicles (as well as short detector errors), one can calculate a more robust estimate of speed using the following equation,

$$
\text { median }(\text { speed })=\frac{\hat{L}}{\text { median }(\text { on }- \text { time })}
$$

The loop data were validated using roughly 325 round-trip, probe vehicle runs through the corridor. Further validation was conducted using COTA AVL data from March 2001-August 2004. Figure 3 shows an example of the COTA AVL data over five consecutive weekdays, the I-71 corridor used in this study runs vertically, roughly through the middle of this figure.

Several major events occurred that impacted measurements or traffic demand during the period of data studied in this research, these events include the following: 
Dec 2001

March 2002

March 2003

June 2003

September 2003

August 2004
FMS "turned on"

I-670 closed between I-71 and Hwy 315

Spring and Long St bridges closed for 3 mo

South innerbelt resurfacing and restriping south/westbound traffic knocks out several detector stations

I-670 reopens, now connects to I-70 on the west end

Polaris interchange rebuilding begins - knocks out several detector stations

The impacts from several of these events will be evident in the analysis below.

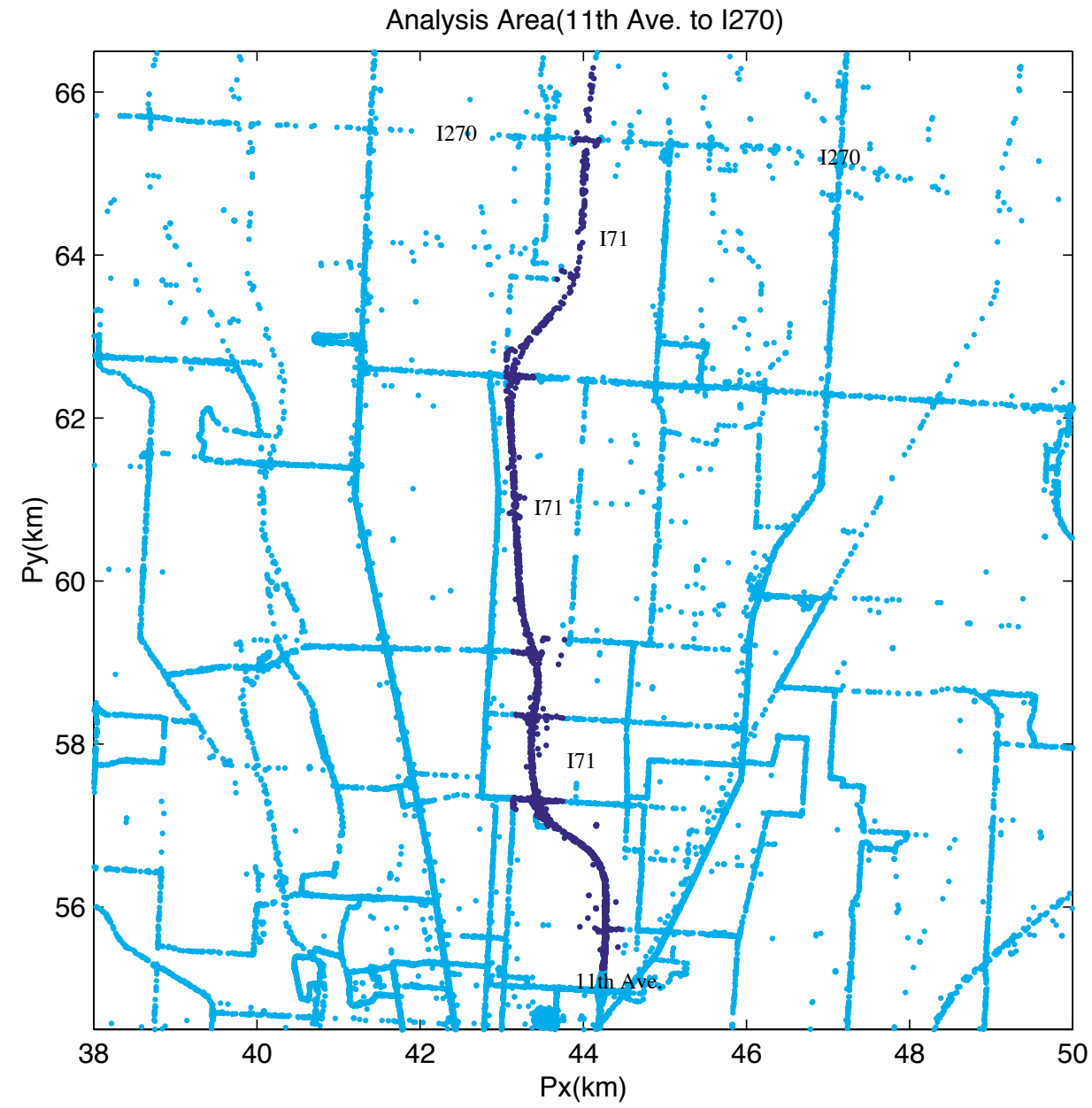

Figure 3, Five days of COTA AVL data, roughly centered on the I-71 corridor running vertically through this plot. 


\section{Data Processing}

The first step of the analysis converts the raw loop transition data into measures and correlating the given loop detector number with the specific location (station and lane) on the freeway. It proved necessary to calibrate the loop detectors in this study, as many of the loops initially provided unreasonable measurements. This process began with the dual loop separation measured by ODOT prior to the start up of the CMFMS. Many errors remained in these measurements, as well as the assumed effective length at the single loop detectors due to varying sensitivity from loop to loop. To address these problems, we took the median speed over a day and found the correction factor to make this median equal to the expected value $(5 \mathrm{mph}$ over the posted limit). These correction factors were further adjusted after comparing concurrent loop and probe vehicle data (e.g., Figures 4-9) and then were subsequently held constant.

It is also important to note that even with the correction factors, the speed measurements from dual loops and estimates at single loops degrade when there are few vehicles in a given sample. The problem arises at dual loops due to misdetection errors and at single loops because the true average or median vehicle length of the sample can deviate significantly from the constant $\hat{L}$ calibrated for samples with mostly passenger vehicles, e.g., if the only vehicle that passes in a sample is a long truck. Fortunately, these errors are relatively easy to catch using an occupancy filter, i.e., free flow traffic is characterized by low occupancy. If there are few vehicles in a given sample and they are free flowing the occupancy will be low, typically below 10 percent. These samples can be corrected to the assumed free flow speed. On the other hand, congested traffic is characterized by occupancies over 15 or 20 percent (see, e.g., [24]). 

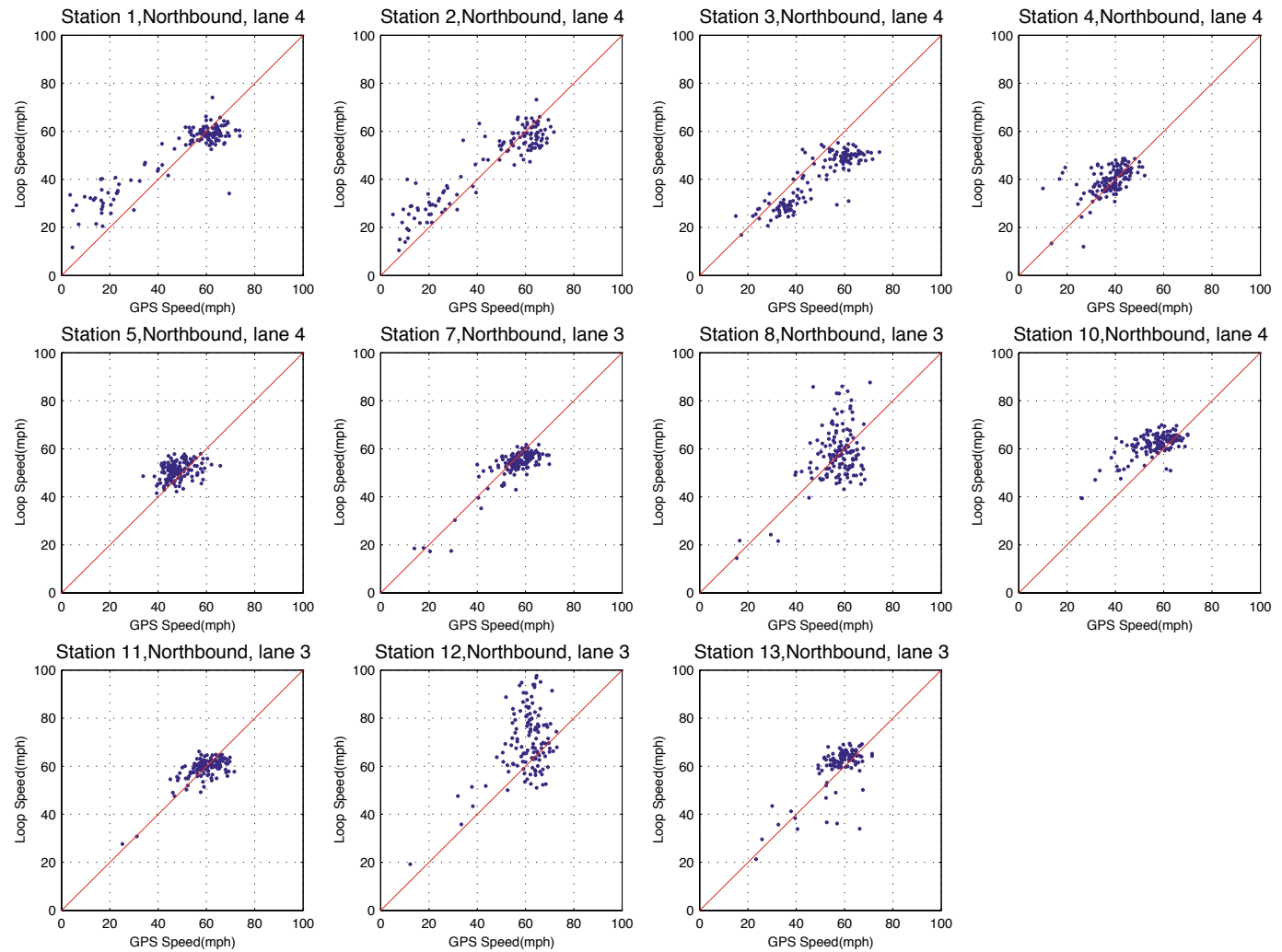

Figure 4, Comparison between loop speed measurements and concurrent probe vehicle speed measurements for several northbound single and dual loops (between 114 and 141 samples per plot).
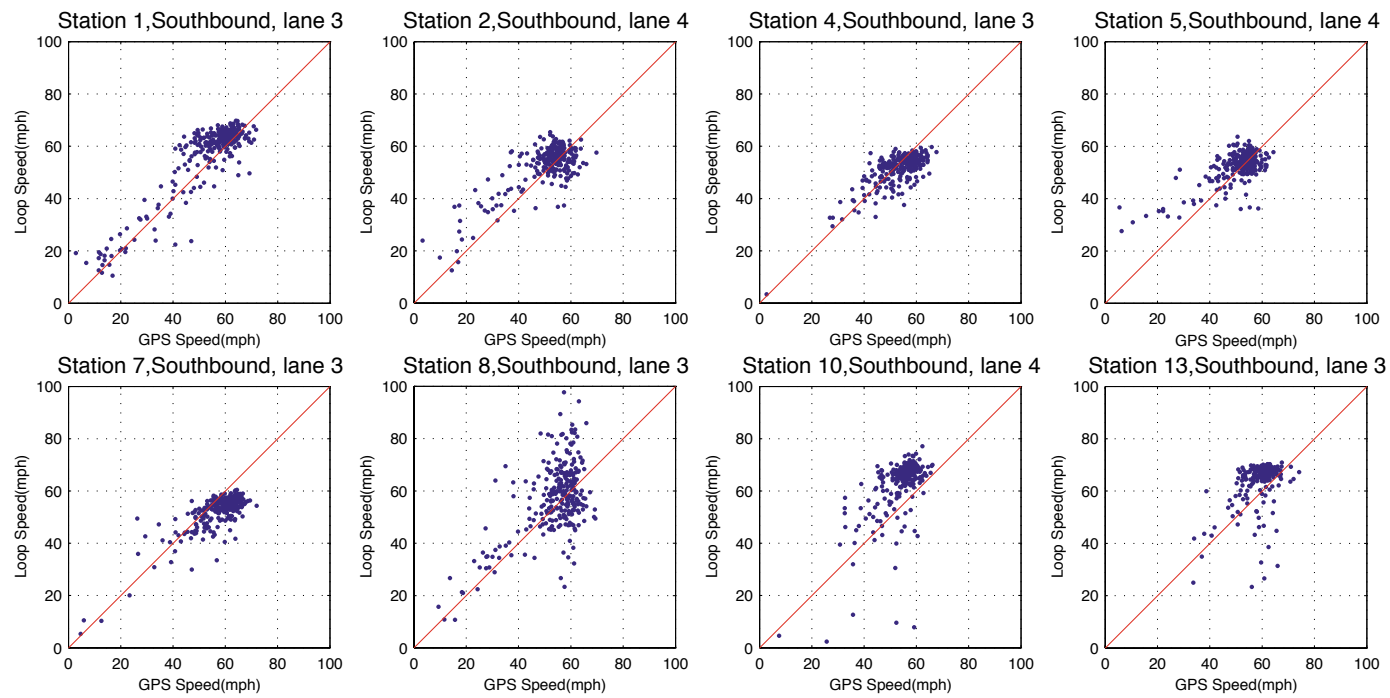

Figure 5, Comparison between loop speed measurements and concurrent probe vehicle speed measurements for several southbound single and dual loops (between 206 and 270 samples per plot). 

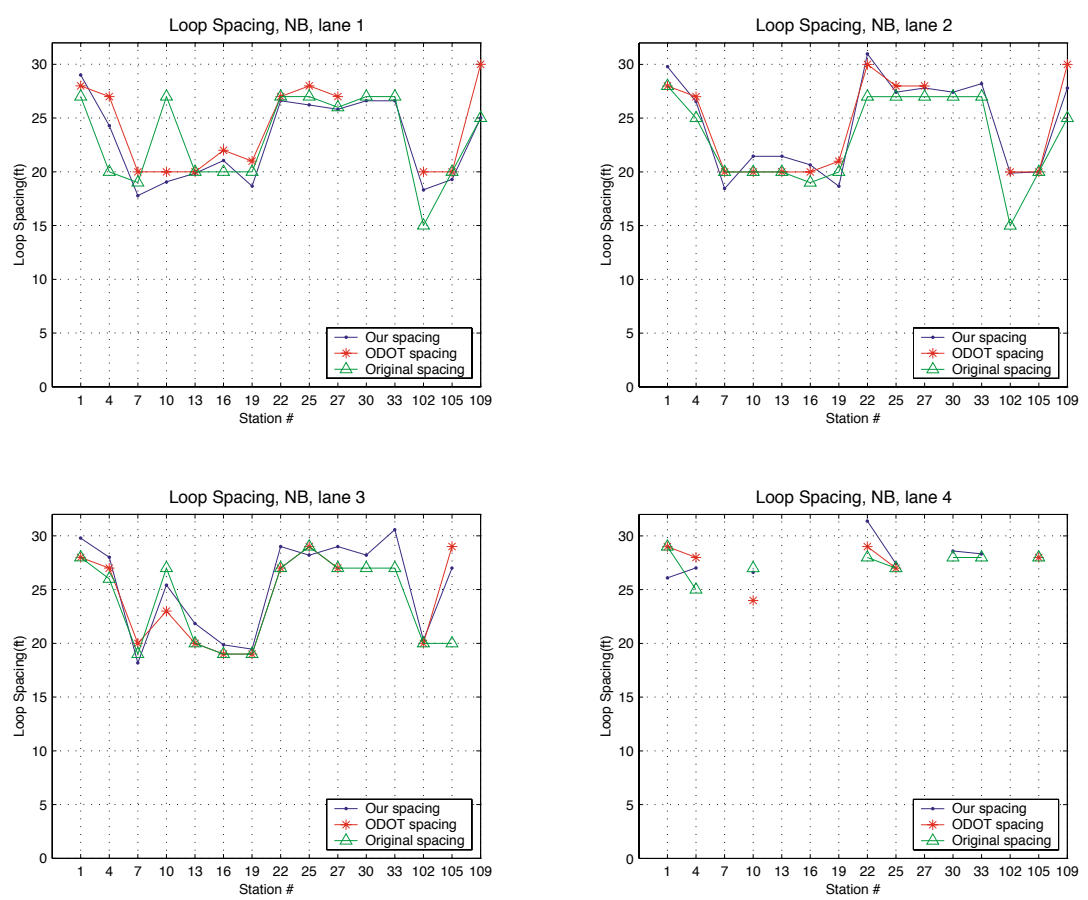

Figure 6, Northbound dual loop separation by lane, incorporating the calibration factors.
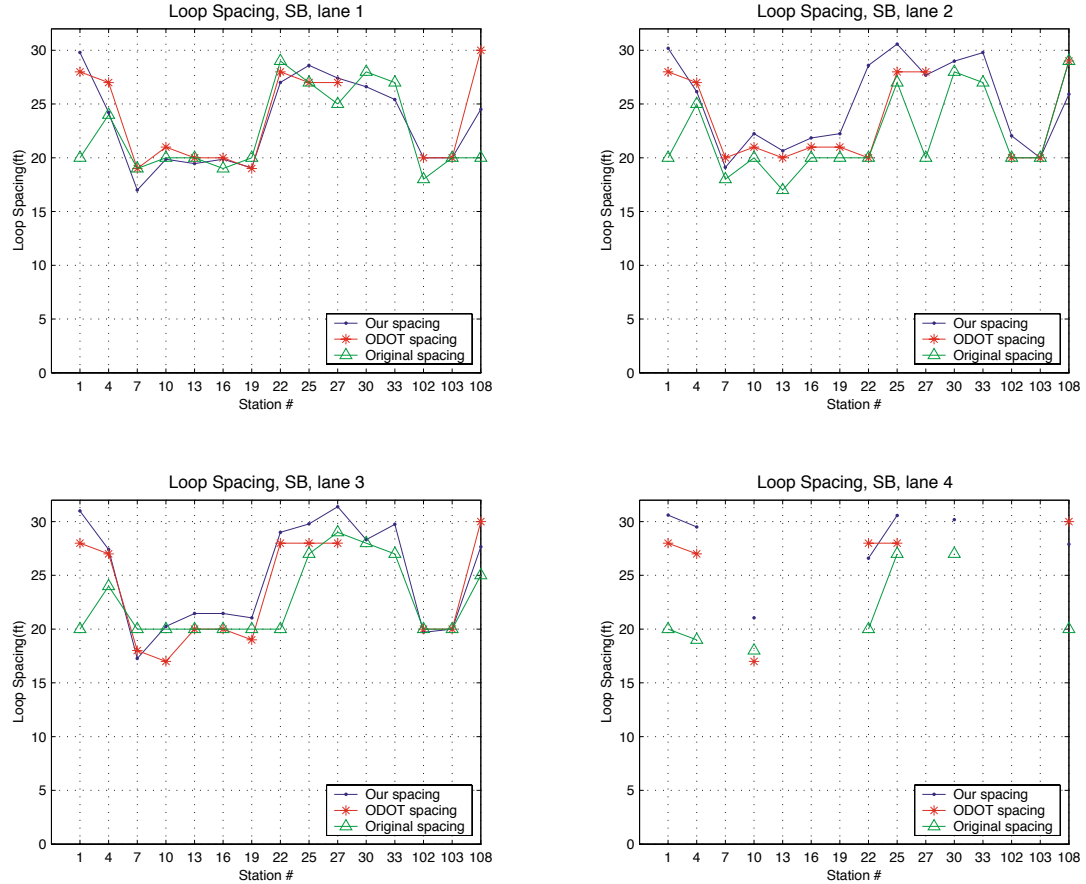

Figure 7, Southbound dual loop separation by lane, incorporating the calibration factors. 


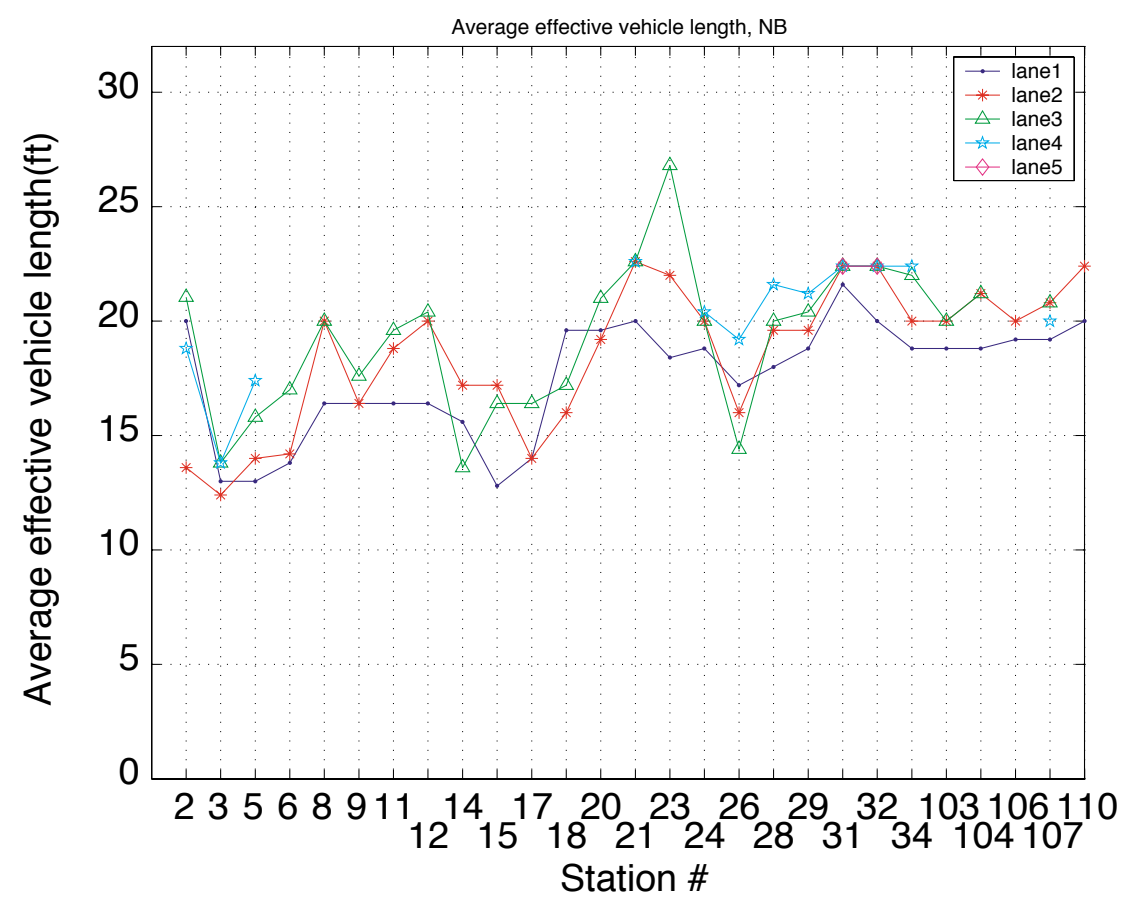

Figure 8, Northbound single loop average effective vehicle length by lane, incorporating the calibration factors.

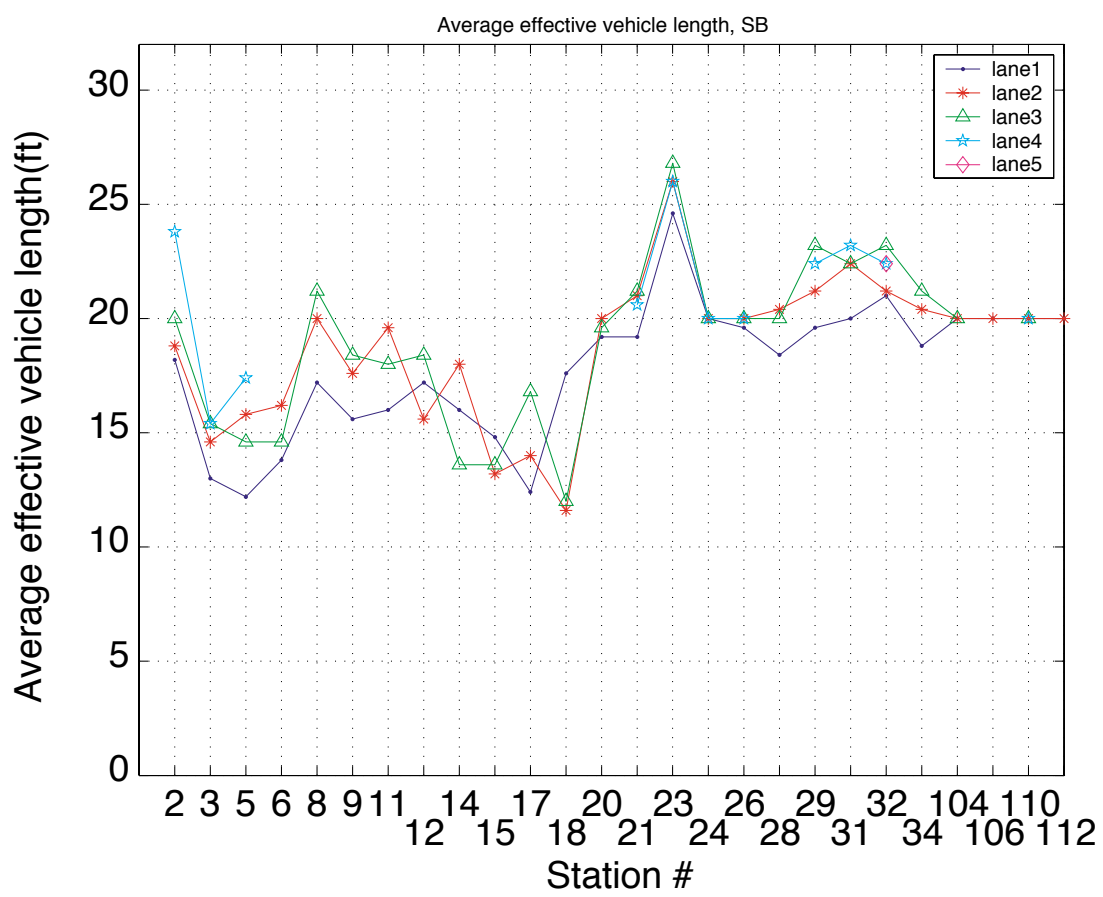

Figure 9, Southbound single loop average effective vehicle length by lane, incorporating the calibration factors. 


\section{Performance Measures}

Many performance measures were developed in the course of this research, although many of these measures are simply refinements on earlier techniques, there were several small but significant advances. The first performance measure is the summary plots, showing directional conditions along the entire corridor over time and space. The next performance measure is estimated travel time and delay. Then we measure average daily travel (ADT), vehicle miles traveled (VMT), and hours of delay. With these latter metrics, the most significant contribution were filters to allow one to clearly view trends over several years of data. Provided an operating agency archives real time traffic data, all of these measures can be generated either in real time or off line.

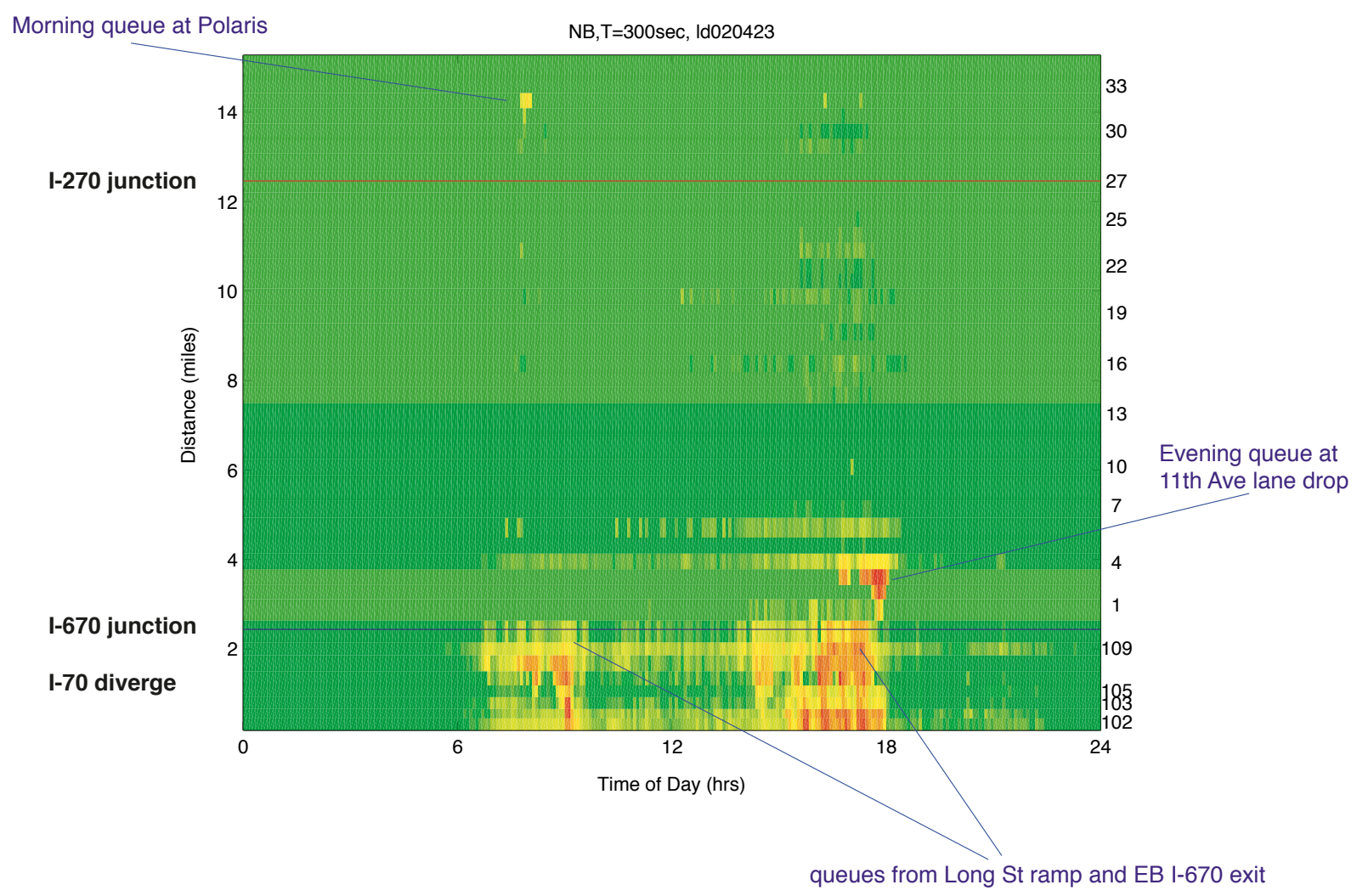

Figure 10, A sample summary plot showing the evolution of traffic conditions over the entire corridor over $24 \mathrm{hrs}$.

\section{Summary Plots}

The basic summary plot shows directional conditions in the form of speed along the entire corridor over time and space. It is essentially a matrix indexed by location and time containing the speeds for that sample. In this study we used 5 min samples with synchronized start time at every station. Links are taken to begin and end at the midpoint between two detector stations 
though one could easily use station to station, or even simply index by station number rather than distance. Finally, we use a continuous gradient between $0 \mathrm{mph}$ (dark red) and $65 \mathrm{mph}$ (bright green), though one could discretize the space to only a few speed bins. Figure 10 shows the summary plot for one day of northbound traffic (direction of travel is from bottom to top). The vertical axis is distance along the roadway, as indicated on the left, with a second axis on the right showing the station number. As indicated on the figure, queuing is evident at four different instances and three different locations in the plot (all recurring bottlenecks in this case).

Daily summary plots can be organized in calendar format to show the traffic state over the entire month. Figure 11 shows an example of such a presentation. The first seven columns show Sunday through Saturday, respectively. If the month starts on a day other than Sunday, the extra cells are populated with data from the end of the preceding month, similarly if the month ends before Saturday, the remaining cells are populated with the corresponding data from the following month. The final column shows the weekday average for that row and the last row shows the column average for that day of the week. This monthly plot includes the data from Figures 10 (fourth row third column, highlighted with a dashed circle). A quick glance at this plot can reveal the queuing due to incidents and recurring bottlenecks alike.

The summary plots also show the operational status of the detectors, if no data were received for a given station at a given time, the cell is left white, indicating a failure somewhere in the surveillance system. Several small outages are apparent throughout the month. Three brief system-wide outages are apparent in this month, as manifest as the vertical white lines in the third and fifth rows. Then, in the fifth row, seventh column, one can see two horizontal white lines, indicating that two detector stations were down the entire day. We will return to this operational status shortly. 


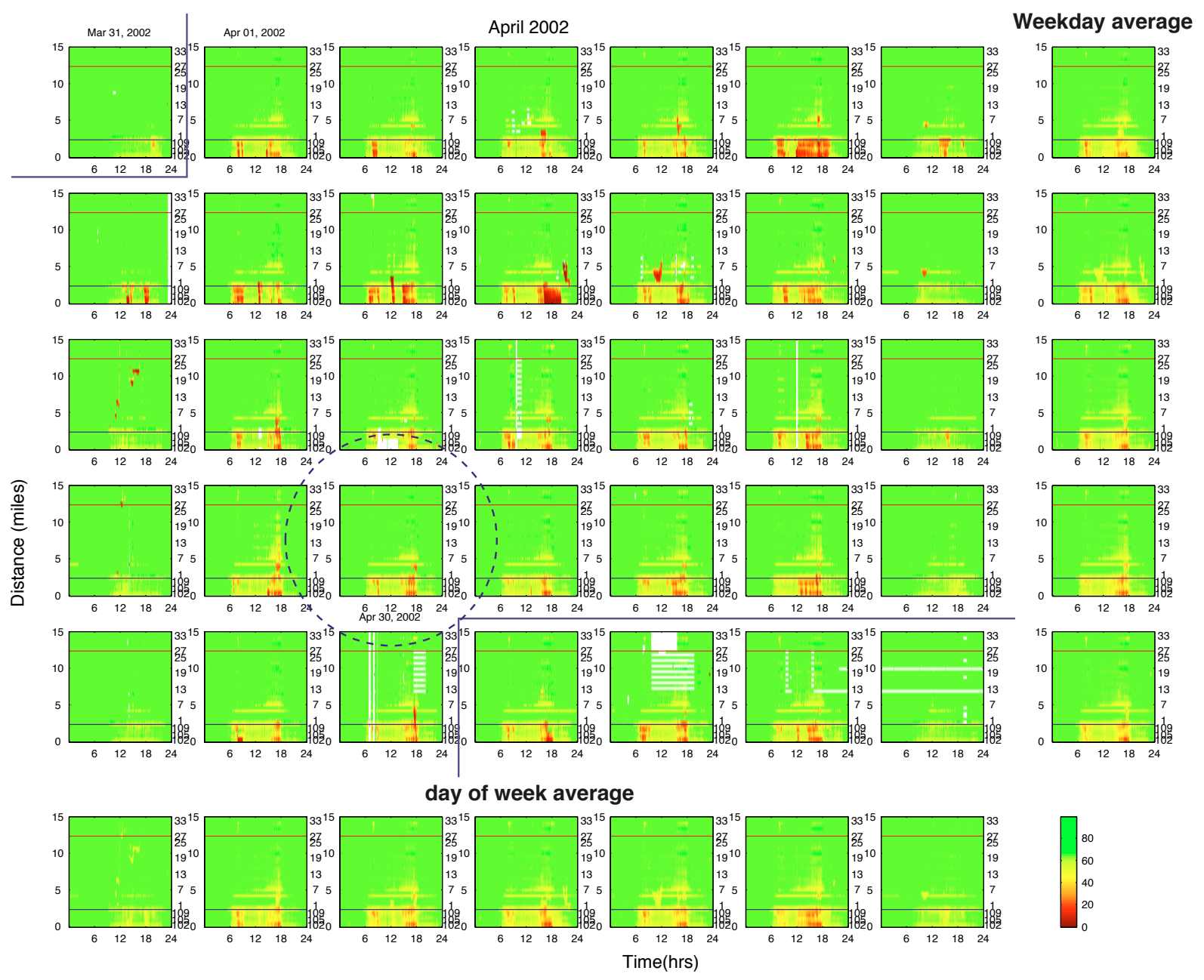

Figure 11, A sample monthly summary plot showing the evolution of traffic conditions over the entire corridor over 30 days.

The monthly data can be summarized to get the average weekday conditions and the average weekend conditions over the month. Taking the difference between the daily conditions and the respective monthly average yields the summary difference plot, e.g., Figure 12 shows the difference plot corresponding to Figure 10. The summary difference plot shows how conditions differ from "normal," highlighting non-recurring events, red denotes slower than average speed and green faster. The fainter the color, the smaller the difference is from the average for that time and location (white indicates no difference). Note that one could also use the average of the last $\mathrm{N}$ days, or the last $\mathrm{N}$ specific day of the week to generate the summary difference plot. Like the summary plot, the summary difference plot can easily be presented for the entire month in the calendar format, e.g., Figure 13. Each cell in Figure 13 corresponds to the same cell in Figure 11. 


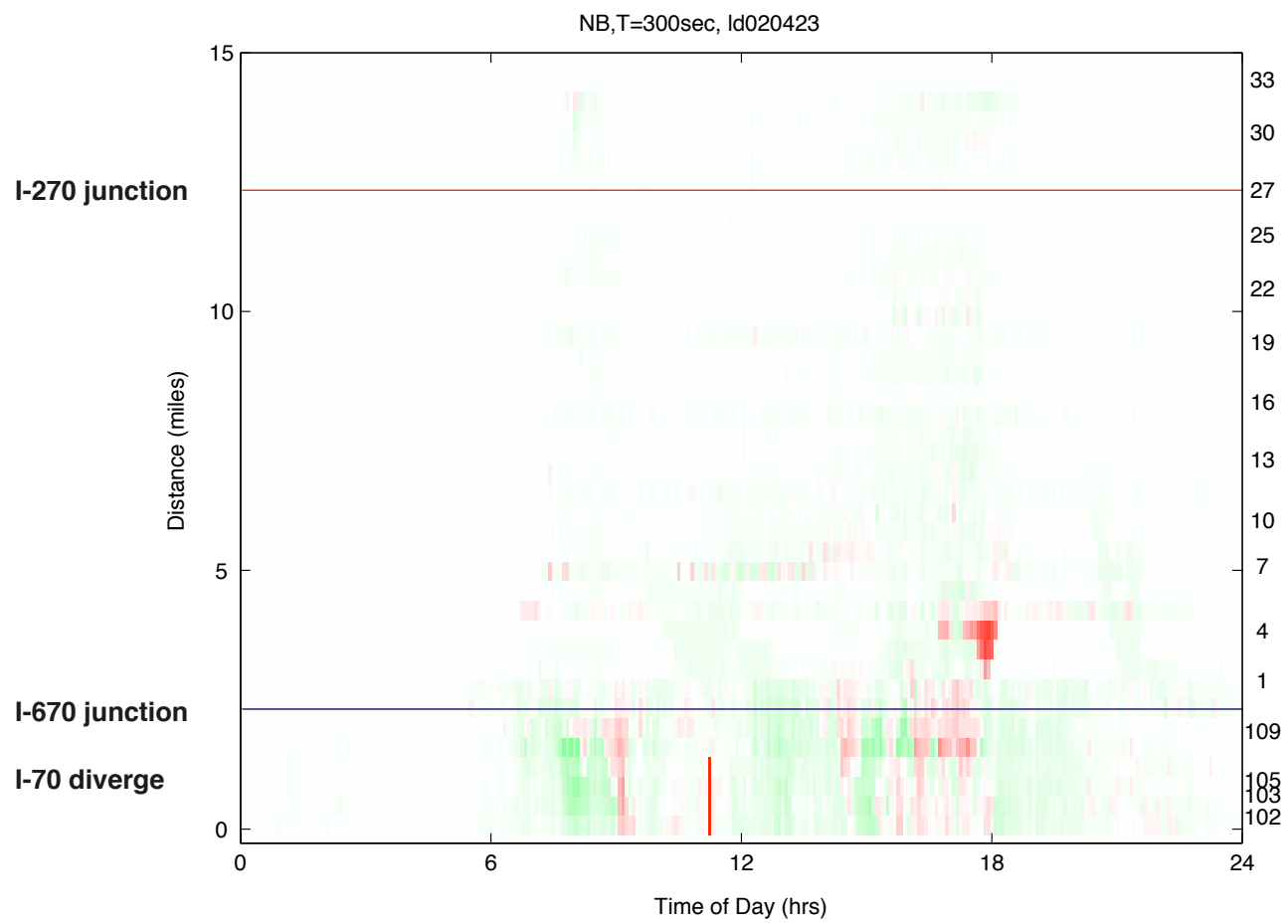

Figure 12, A sample summary difference plot showing the evolution of traffic conditions over the entire corridor over $24 \mathrm{hrs}$. 


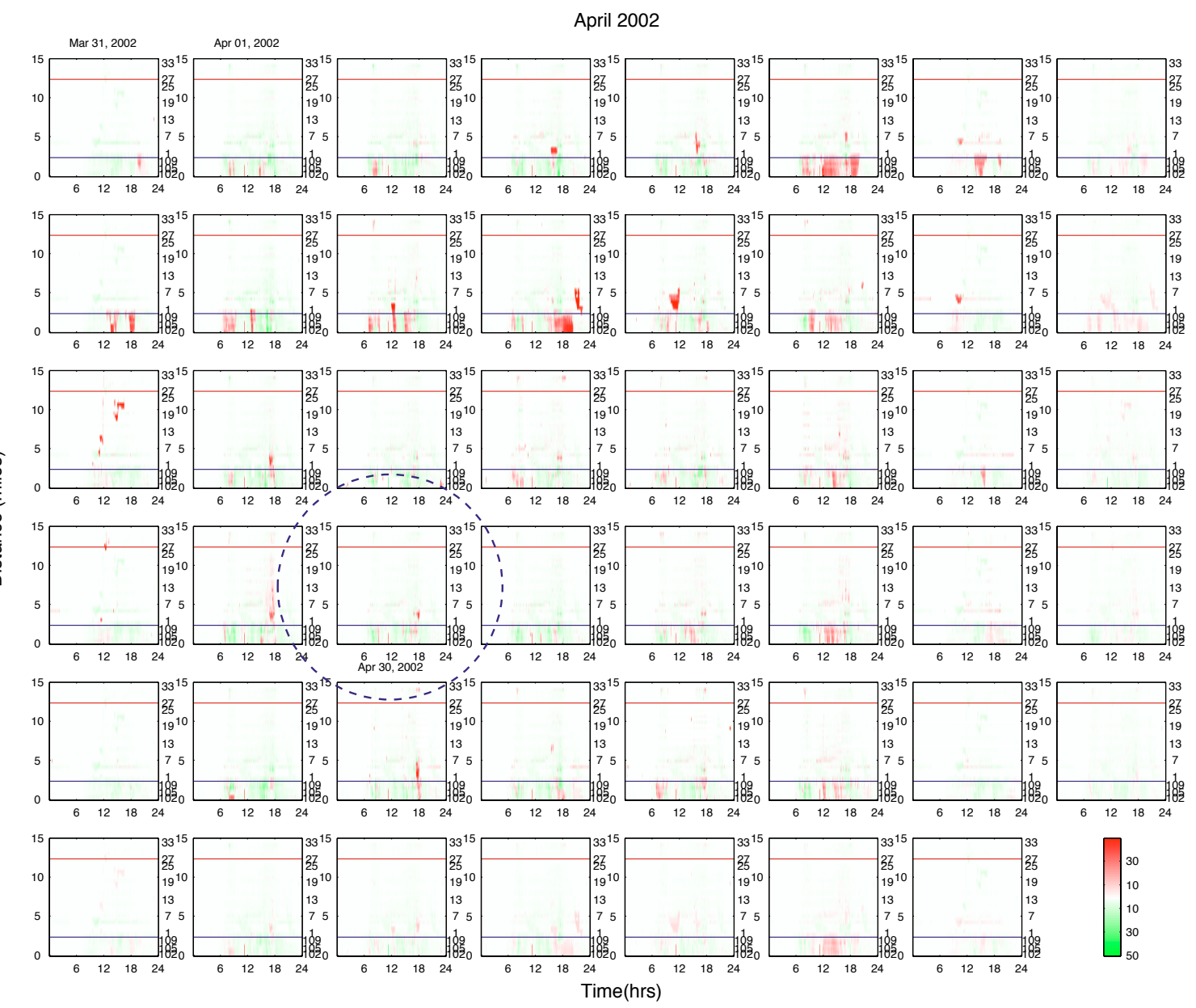

Figure 13, A sample monthly summary difference plot showing the evolution of traffic conditions over the entire corridor over 30 days.

Returning to the operational status of the detectors, consider the evolution of the system. Figure 14 shows the first month of data, it is characterized by frequent communication outages, but all stations report data (note that the averages are dimmed to avoid confusion with the daily measures). Figure 15 shows the system one year in, this month is characterized by a few outages and one station is down for most of the month (the horizontal white line in each cell). Figure 16 shows the results of resurfacing on the south inner belt, knocking out all 170 stations (the bottom of each cell) starting June 7th, 2003. Two months after resurfacing, Figure 17 shows that most of loops have been re-cut, but the noisy data from these stations indicate that the new loops are not wired correctly (which was later verified by field visits) and some outages are evident elsewhere on the corridor. Figure 18 shows the status of the corridor two yeas after it was turned on. The I70 stations are now all back but continue to give noisy data. Two stations were down all month and the northern-most stations go down for about a month. The northern most stations were knocked out again in August 2004 due to interchange work, as evident in the top of Figure 19. Finally, Figure 20 shows the state of the system three years after it was turned on (the last few cells were left blank because the following month had not yet been processed). 


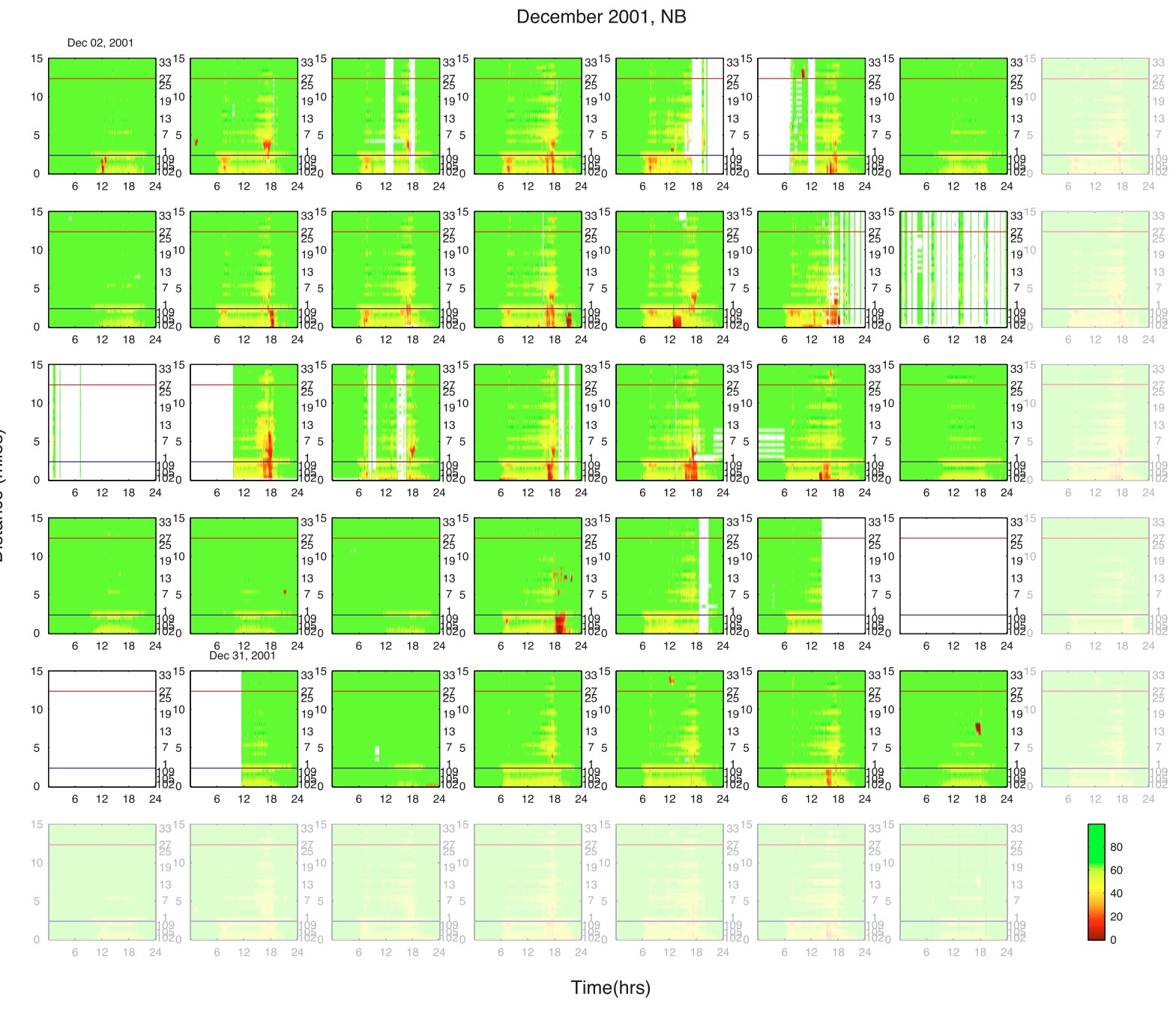

Figure 14, Northbound summary plot for December 2001. 


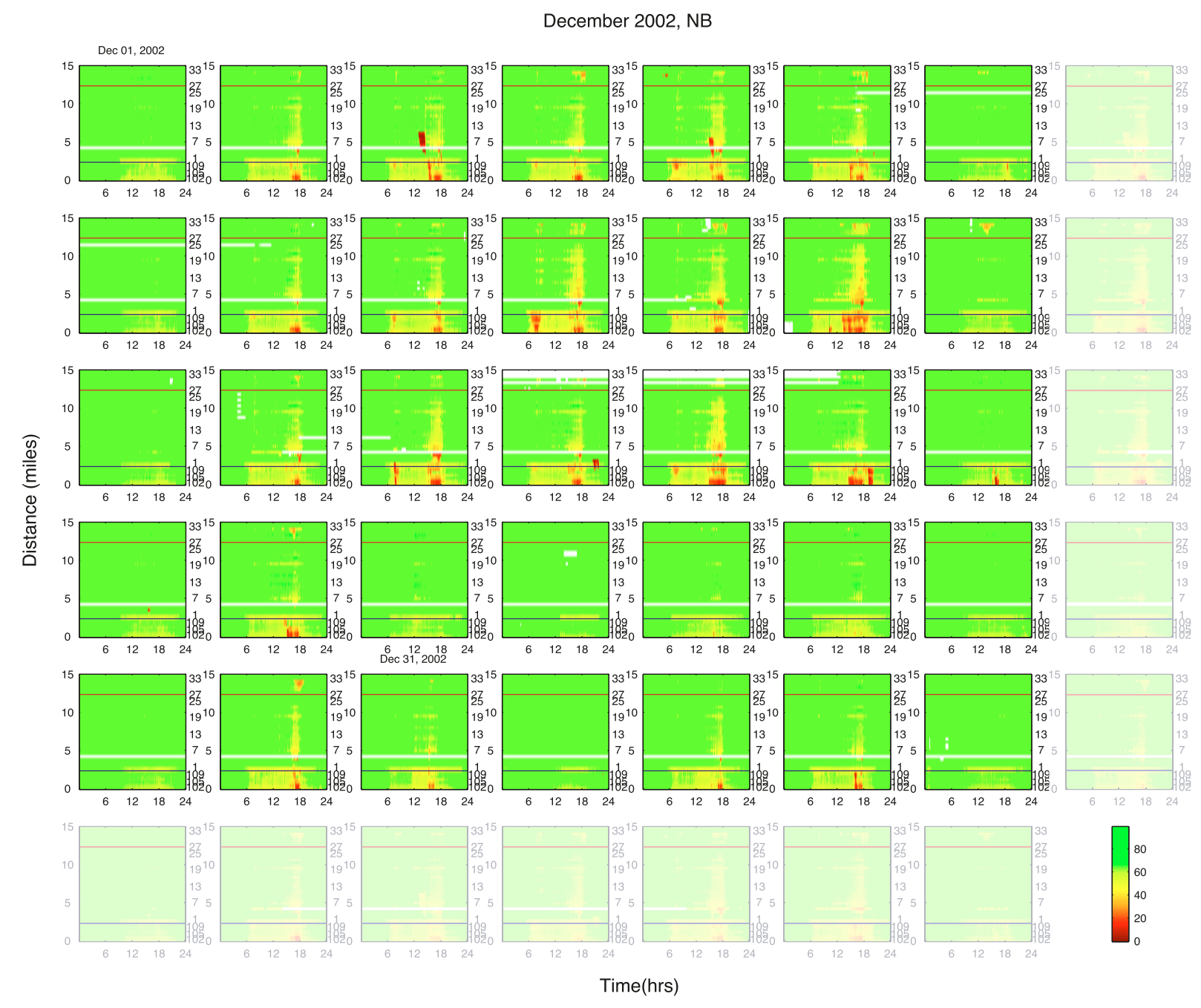

Figure 15, Northbound summary plot for December 2002. 
June 2003, NB
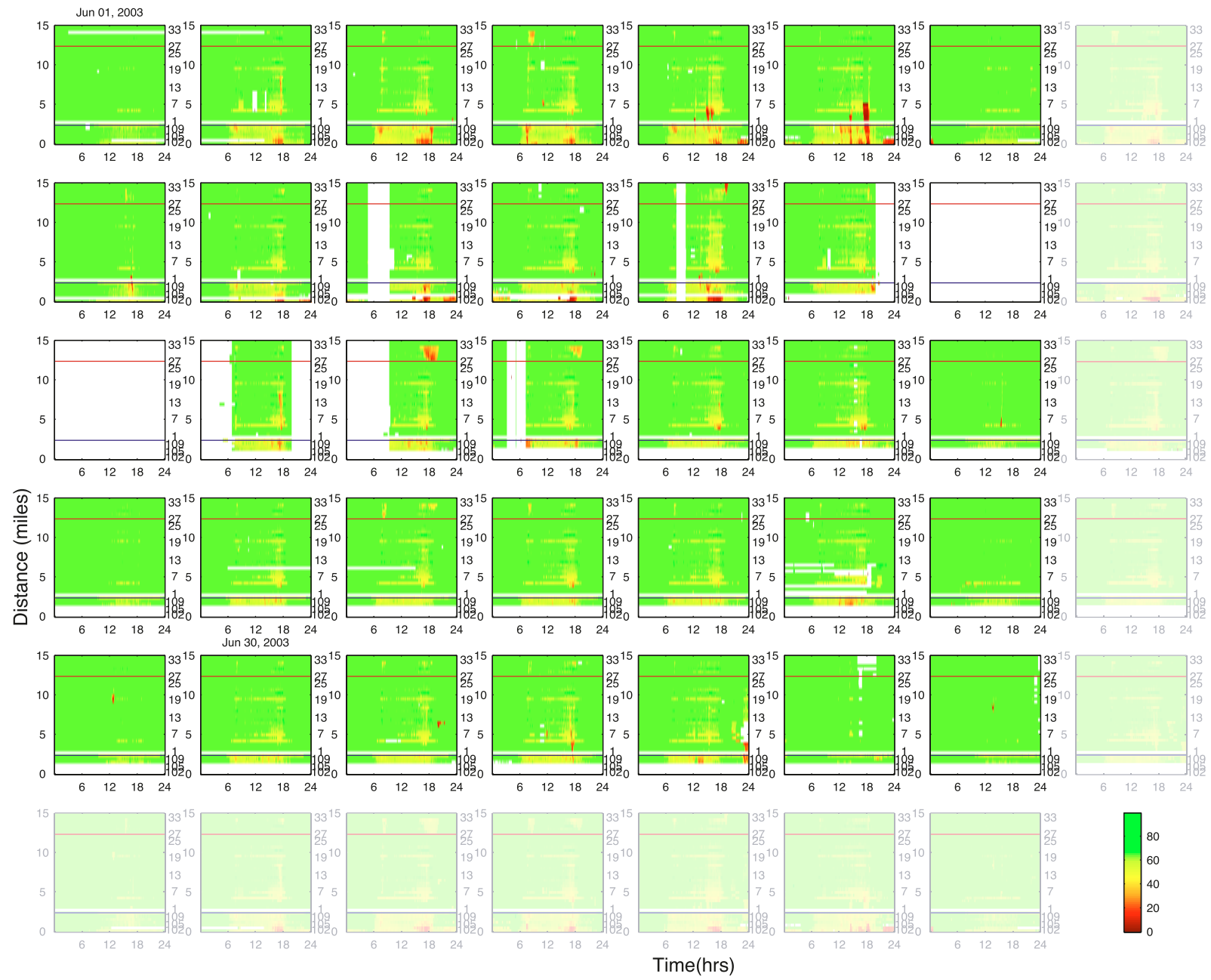

Figure 16, Northbound summary plot for June 2003. 
August 2003, NB
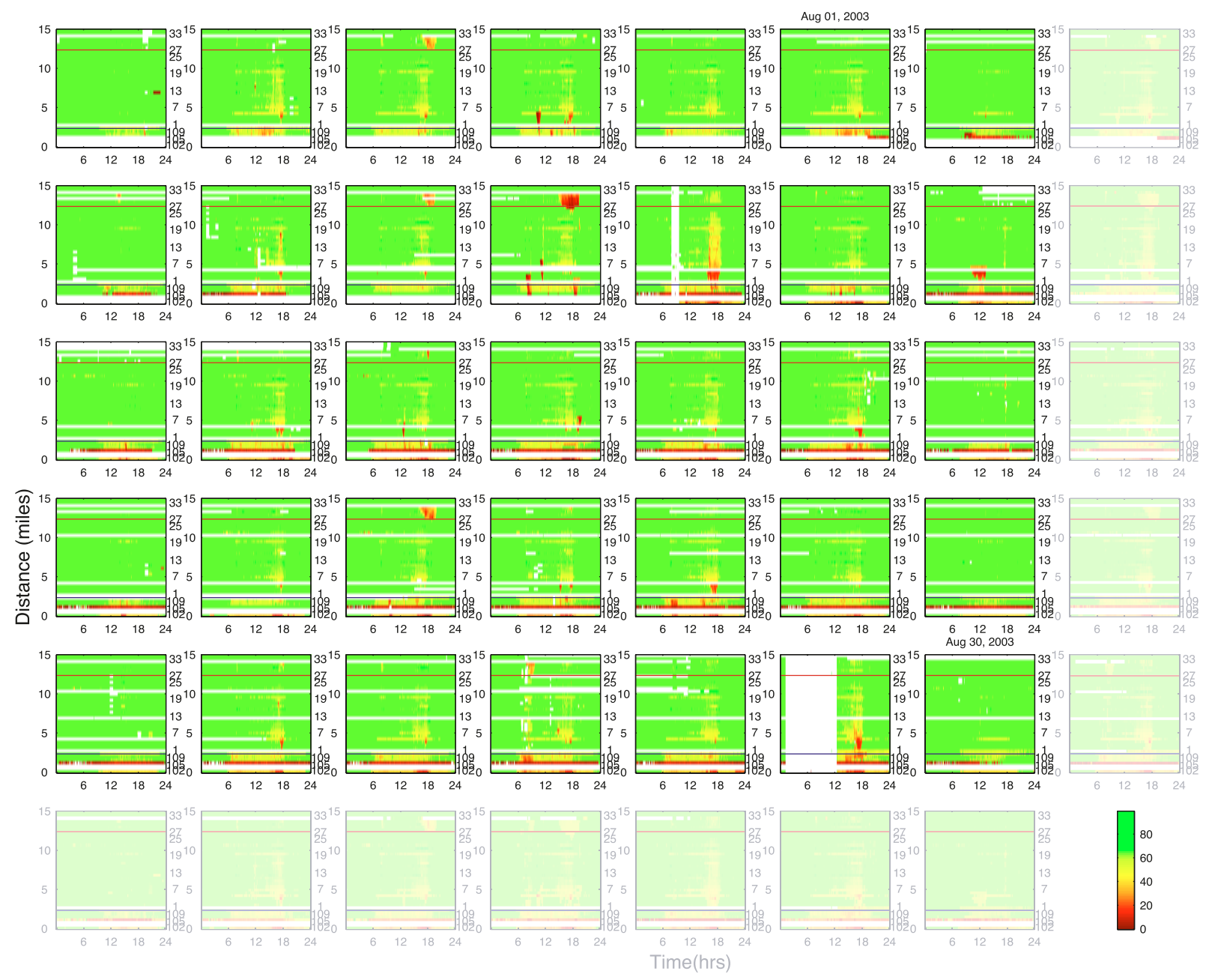

Figure 17, Northbound summary plot for August 2003. 


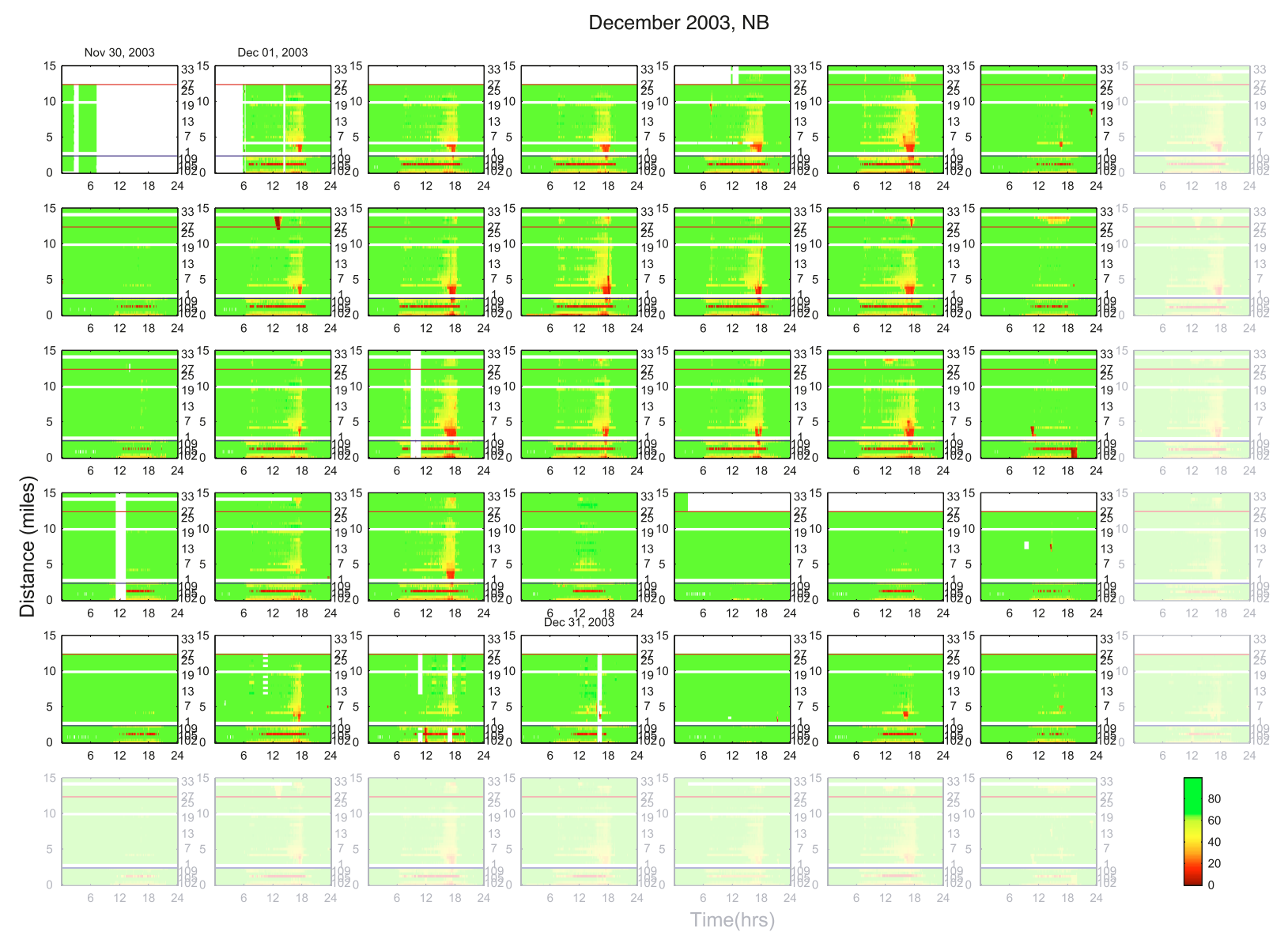

Figure 18, Northbound summary plot for December 2003. 
August 2004, NB
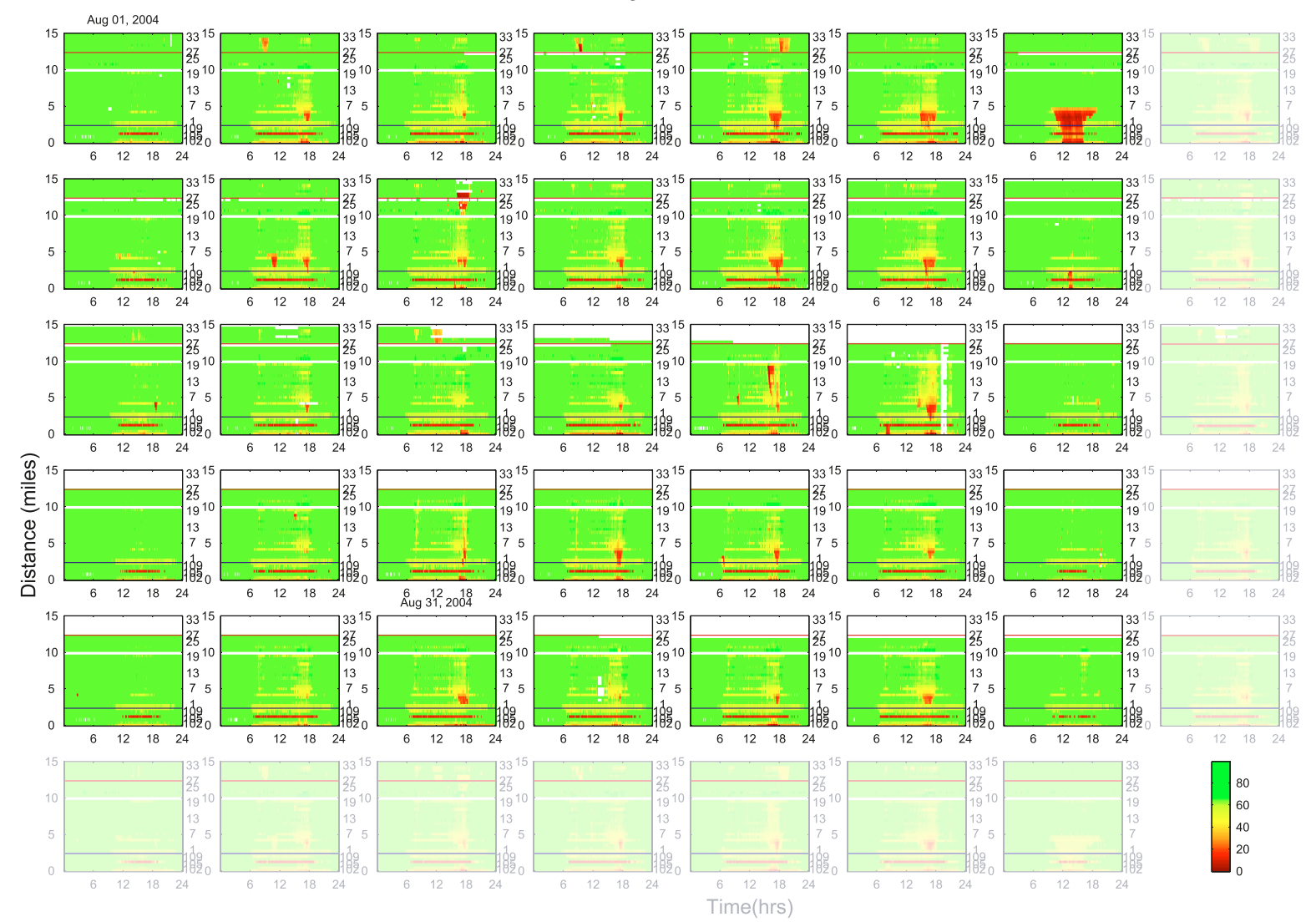

Figure 19, Northbound summary plot for August 2004. 


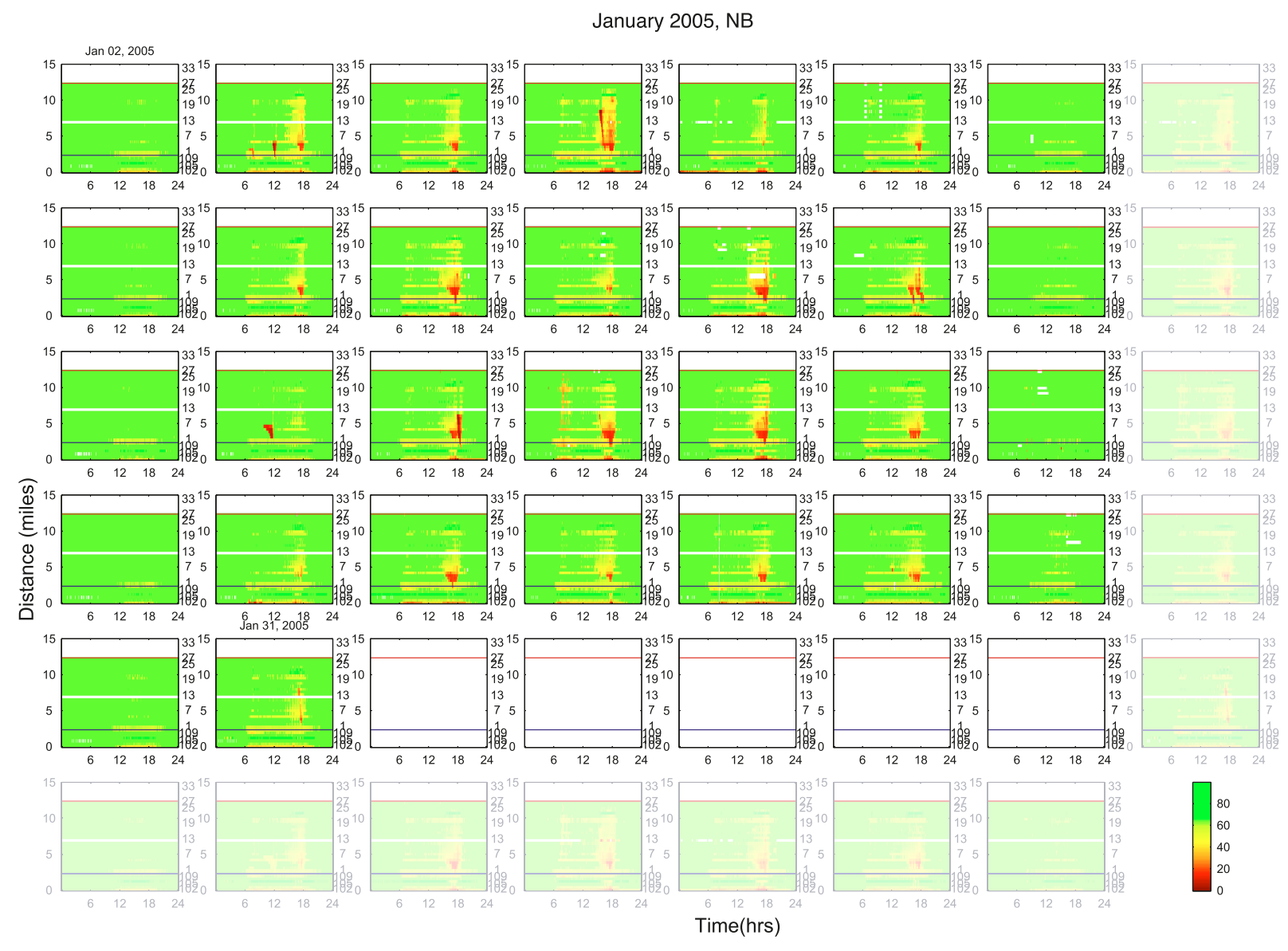

Figure 20, Northbound summary plot for January 2005.

Formalizing a measure of operational detectors, we define,

$$
\text { Opeational }\left(\text { station i) }=1-\frac{\sum_{\text {day }=1}^{N} \# \text { lanes reporting }}{\# \text { lanes } \mathrm{x} N}\right.
$$

Figure 21 shows this measure applied to the data from the entire year of 2004. The plot shows the major problems discussed with regard to Figures 19 and 20, as well as smaller problems at other stations, e.g., 13. This plot could easily be repeated on a monthly or daily basis. 
Northbound, 01/2004 through 12/2004
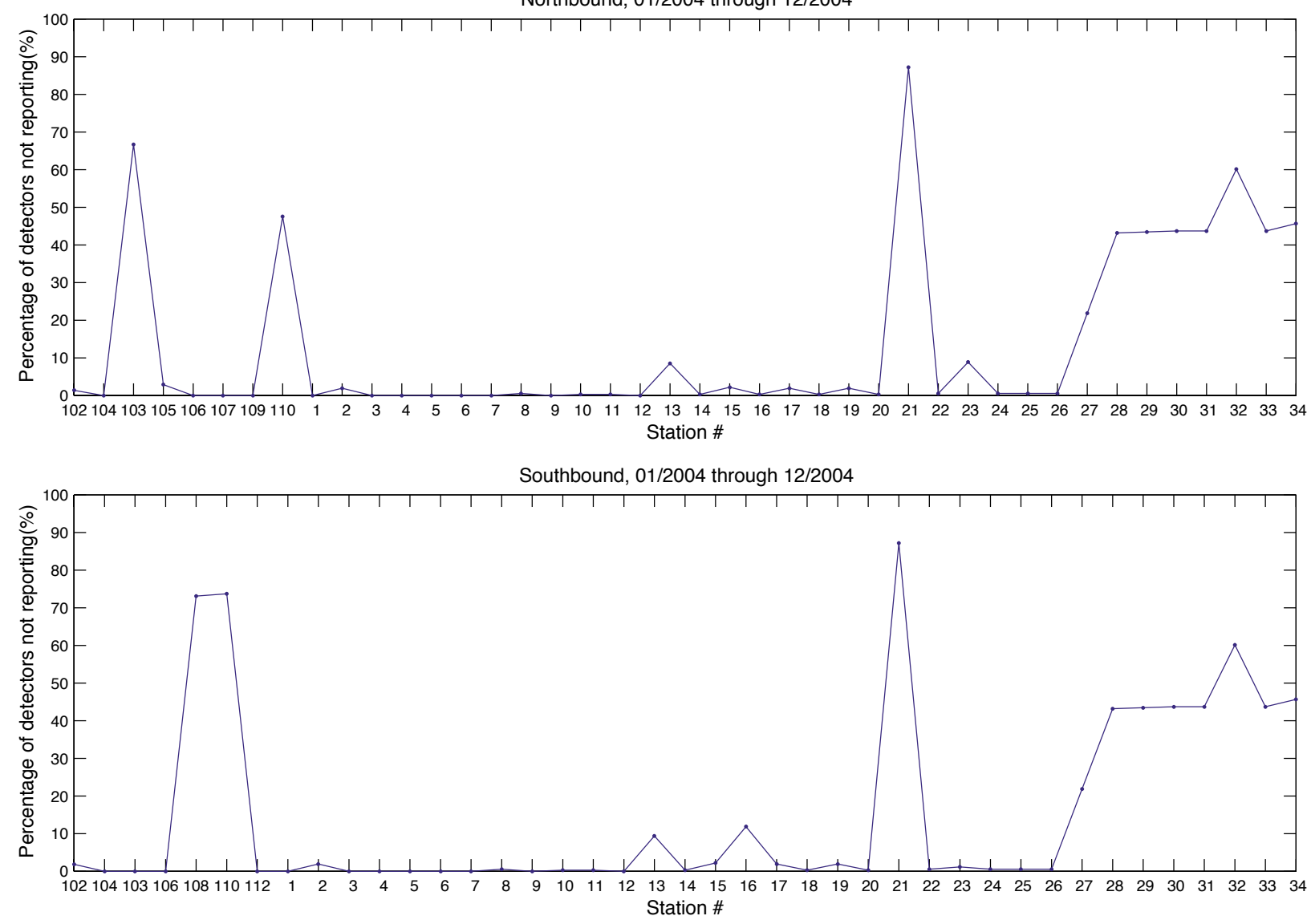

Figure 21, Operational detectors for the calendar year 2004, top plot shows northbound, bottom shows southbound.

\section{Travel Time and Delay}

This research considered several measures and estimates of delay. The simplest approach simply sums successive link distances divided by the current speed at the loops to estimate the travel time on the extended segment. With the individual vehicle measurements provided by the CMFMS it is actually possible to estimate vehicle trajectories over an extended link from local data at a detector station [25]. In fact with the individual vehicle actuations it is even possible to reidentify vehicles and measure the true travel time between loop detector stations [26, 27]. For this research effort, it was decided that the individual vehicle actuations would not be used directly, since these data are uncommon from most traffic monitoring systems.

Constraining the research to conventional aggregated data from the detectors, the simplest estimate discussed above does not capture conditions experienced by any one traveler, it is a cross-section capturing instantaneous conditions. Without more sophisticated forecasting, it is the best one can do for real time systems. But for this project it was chosen that for all historical travel times we would better approximate conditions experienced by travelers. Specifically, we use the speed matrix and link spacing underlying the summary plot, e.g., Figure 10, assume that 
conditions remain constant on a given link for the entire 5 min sample and distance spanned by the link, then estimate vehicle trajectories assuming that vehicles traveled at these prevailing conditions. So trajectories change slope at the boundaries of the cells, either at the end of a link or at the end of a 5 min smple. From the trajectories one can estimate travel time directly, taking the difference in times that a trajectory pass the chosen start and end points. Figure 22 shows one such estimated trajectory against a measured trajectory from the probe vehicle data. This procedure was validated by comparing the estimated travel times to the measured travel times for

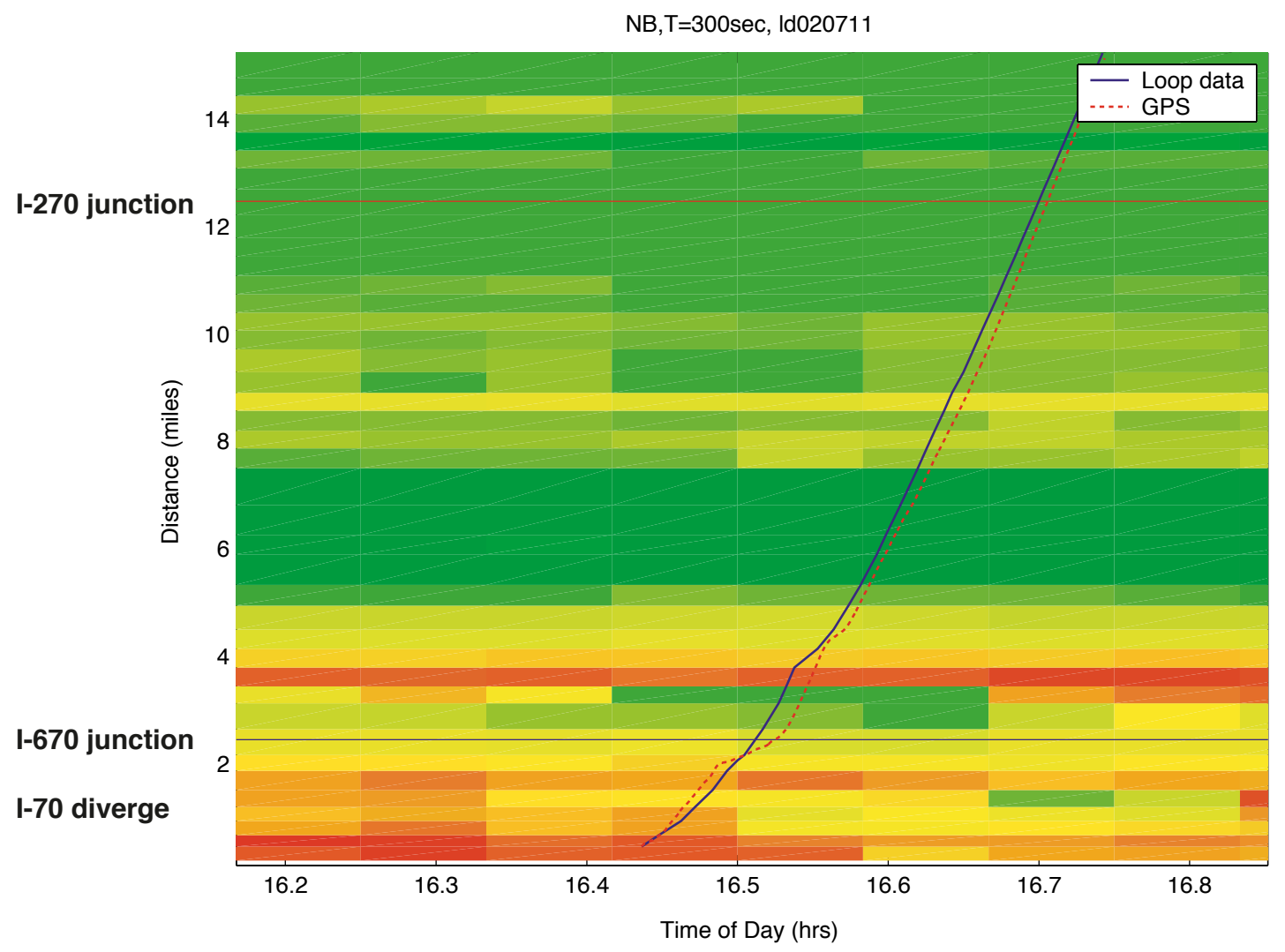

Figure 22, Estimate trajectories then find time between two locations to estimate travel time. Each cell of the velocity summary plot is 5 min by the length of the link. Vehicles are assumed to traverse each cell at the constant cell speed, changing only at cell boundaries.

over 100 probe vehicle tours, with each tour broken into several segments, ranging from 2 mi to $10 \mathrm{mi}$, (see the scatter plots of Figure 23-24). The travel times were also compared against the COTA AVL data, e.g., Figure 25 shows 598 independent measurements over five consecutive weekdays. Some errors remain in these latter plots because it is difficult to distinguish between vehicles on ramps and overpasses and those still on the main line, and the AVL system sometimes introduces a delay to the time stamp. 

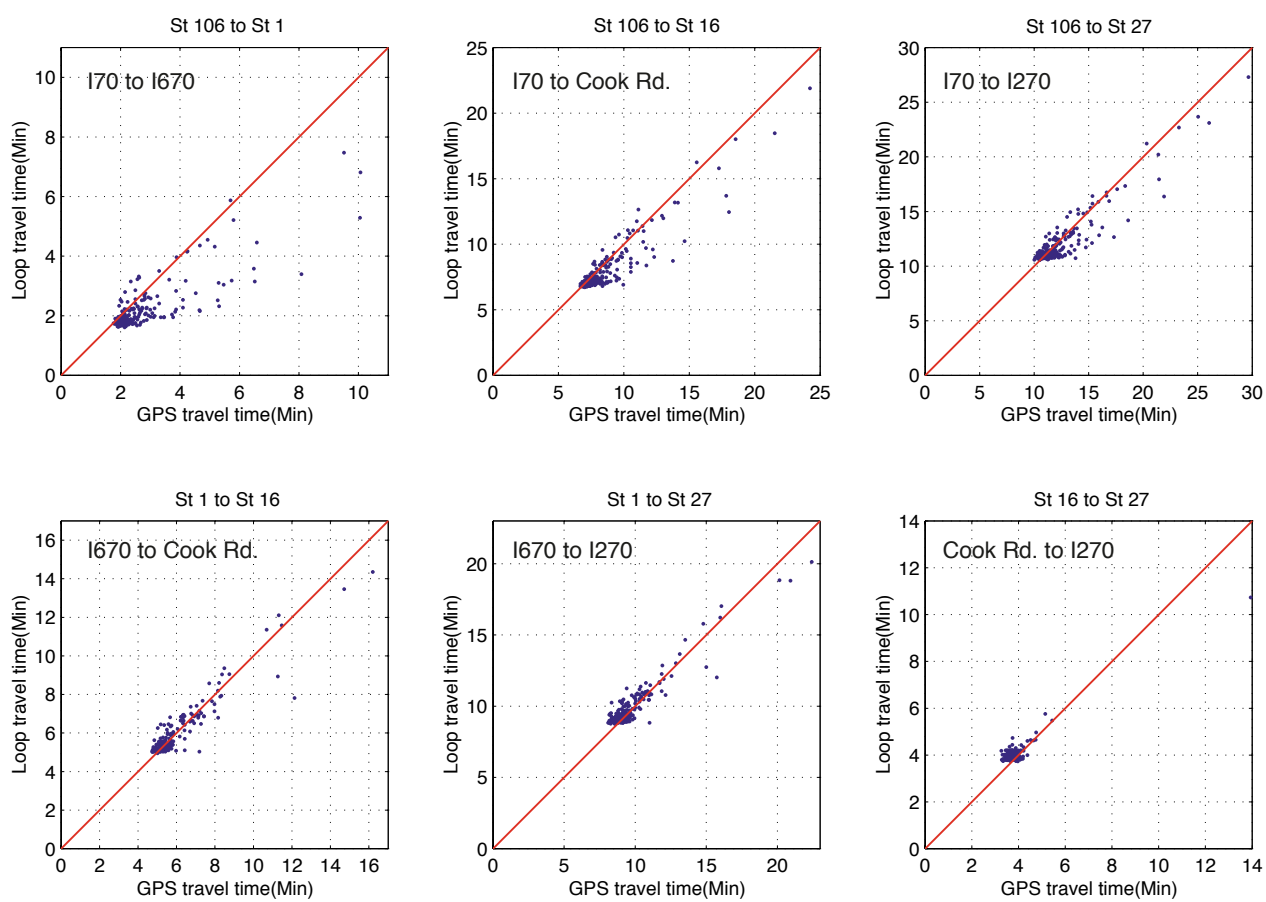

Figure 23, Comparisons between loop estimated travel times and probe vehicle measured travel times, northbound.
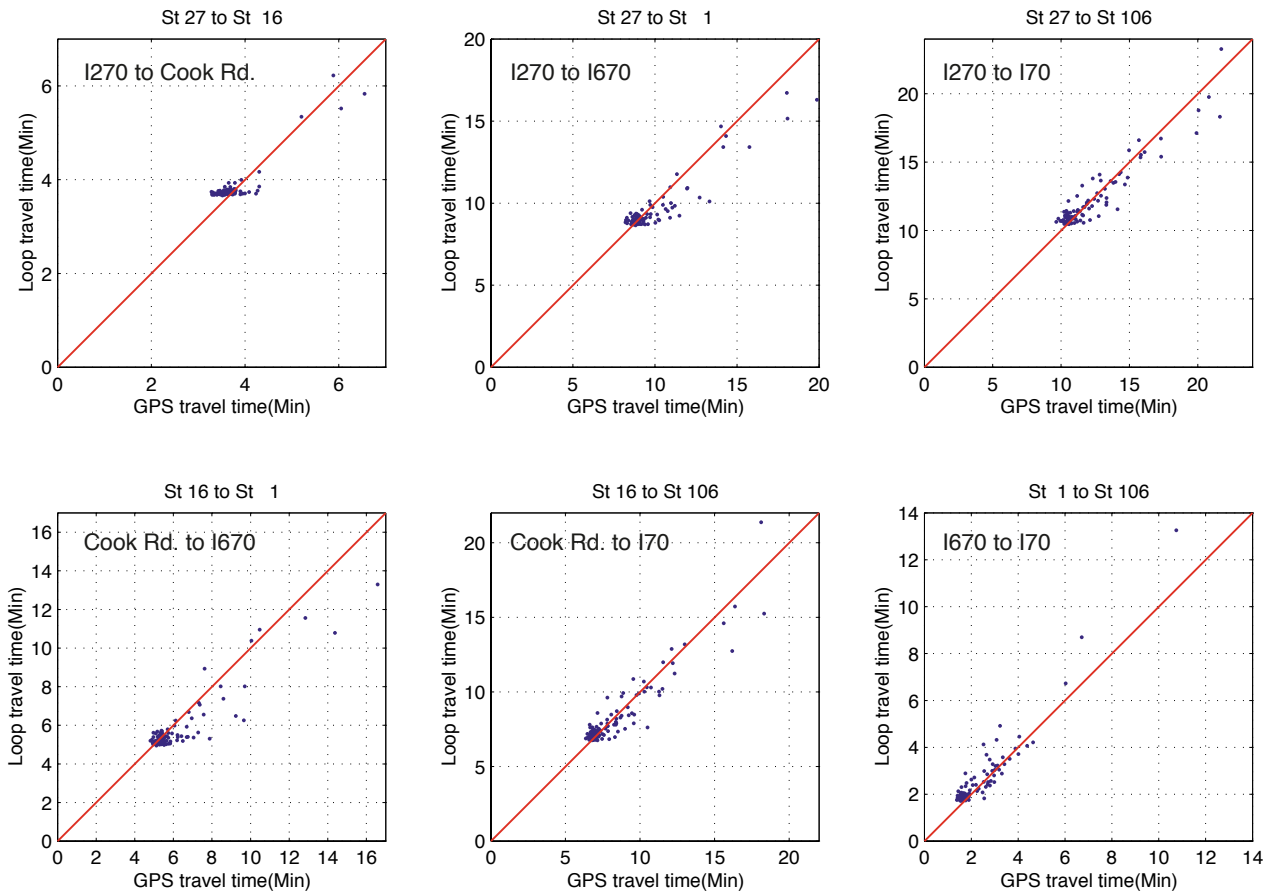

Figure 24, Comparisons between loop estimated travel times and probe vehicle measured travel times, southbound. 

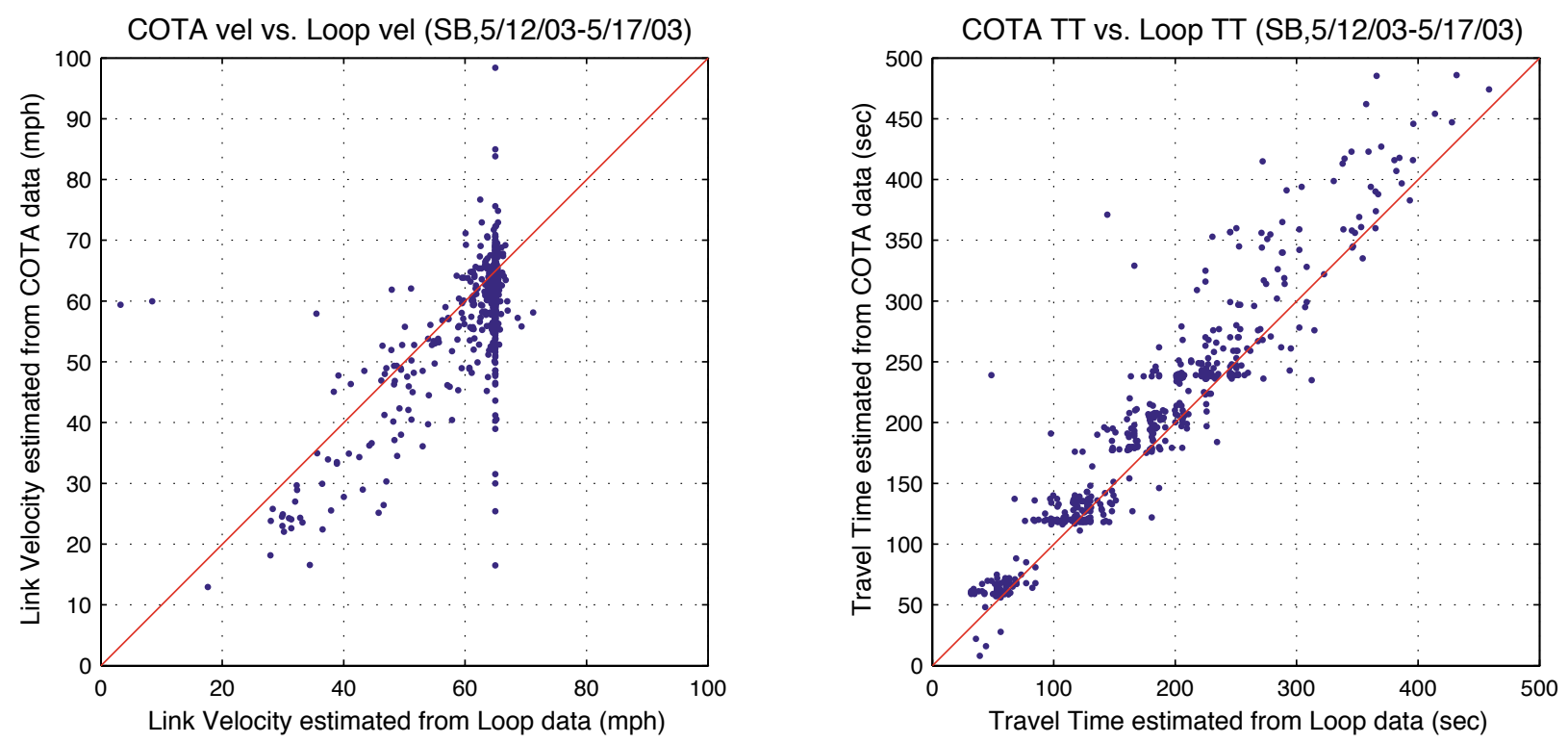

Figure 25, Comparisons between loop estimated travel times and COTA AVL measured travel times, southbound.

This travel time estimation can be applied to a specific start time and location, as was done in the preceding validation. Or, as we do in standard application, applied every five minutes through the entire day at a given start location. These data can then be presented in a time series for that day. Statistics over several days can also be calculated, e.g., Figure 26 shows the mean and median travel times as a function of start time for two different links over an entire month. One can easily produce the min and max, or other percentiles over $\mathrm{N}$ days, or the $\mathrm{N}$ preceding specific day of the week. Such statistics can yield easy to report measures of reliability, e.g., the 95th percentile travel time. Such measures are origin and destination specific, while an operator may be interested in many origins or many destinations. So one can also plot the data in the form of equi-travel time contours. Figure 27B shows lines of equi-travel times from mile 0 , as extracted from the speed data in the summary plot shown in Figure 27A. Traffic flows from bottom to top and most of the congestion in this figure is due to queuing upstream of a recurring bottleneck at mile 2.5. A queue behind an incident is visible starting around noon at mile 3 and lasts about an hour. This extraction can be generalized, averaging across several days (median day, mean day, 95th percentile, etc.), and the presentation tailored for the general public. 
Station 106 to 102 SB
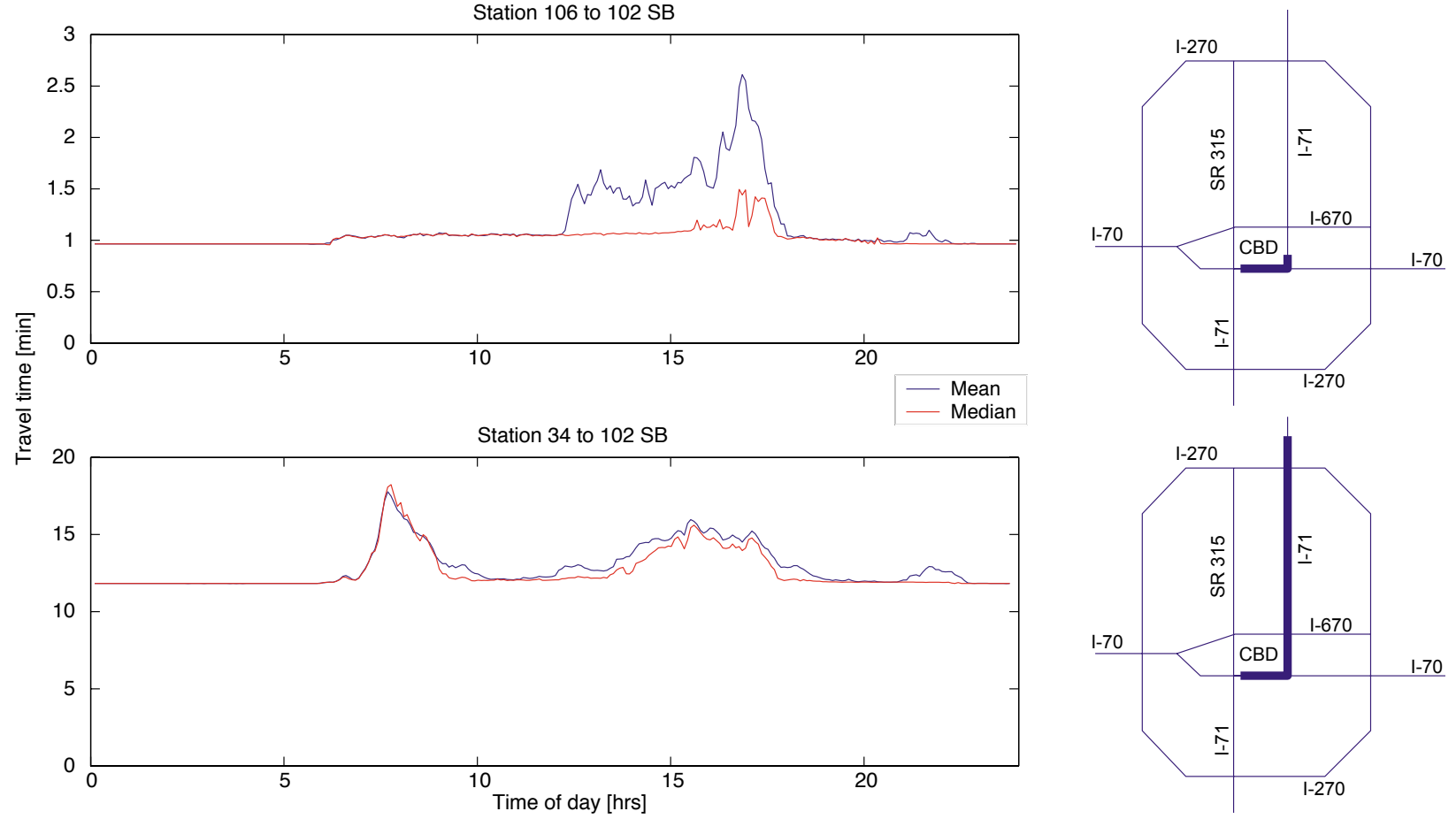

Figure 26, Mean and median travel times as a function of start time for two different southbound links (shown on the right) over an entire month.

A)

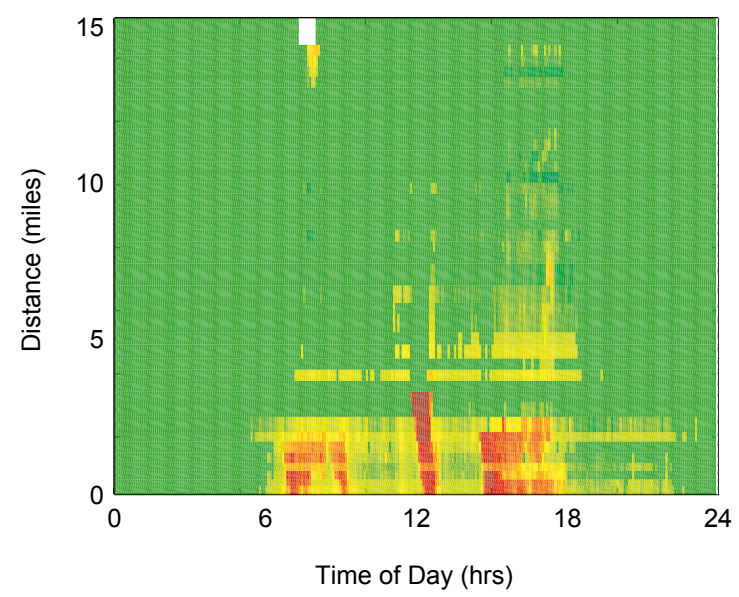

B)

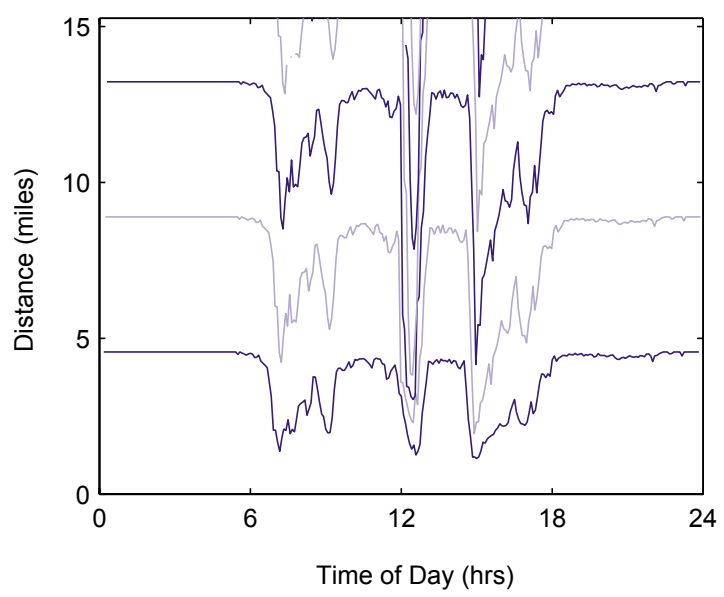

Figure 27, (A) Speed summary plot along the instrumented section of I-71 on a sample day. (B) Corresponding curves of equi-travel time from mile zero shown at 5 min intervals. 
Of course a travel time estimate allows an agency to estimate delay. In our study, we define delay to be travel below $55 \mathrm{mph}$. For a given five minute sample and link, we take the delay for each vehicle to be:

$$
\text { total vehicle delay }=\text { flow } \cdot \max \left(\frac{\text { link distance }}{\text { speed }}-\frac{\text { link distance }}{55 \mathrm{mph}}, 0\right)
$$

resulting in a delay matrix of the same size as the speed summary matrix. One can then sum across rows (delay at a link over a day), columns (delay across the corridor at an instant) or any other region of the matrix, e.g., Figure 28. In this case, the delay due to the incident within the instrumented area is 287 veh-hrs and a total of 971 veh-hrs of delay were measured. The average weekday in this month had 390 veh-hrs of delay.

A)

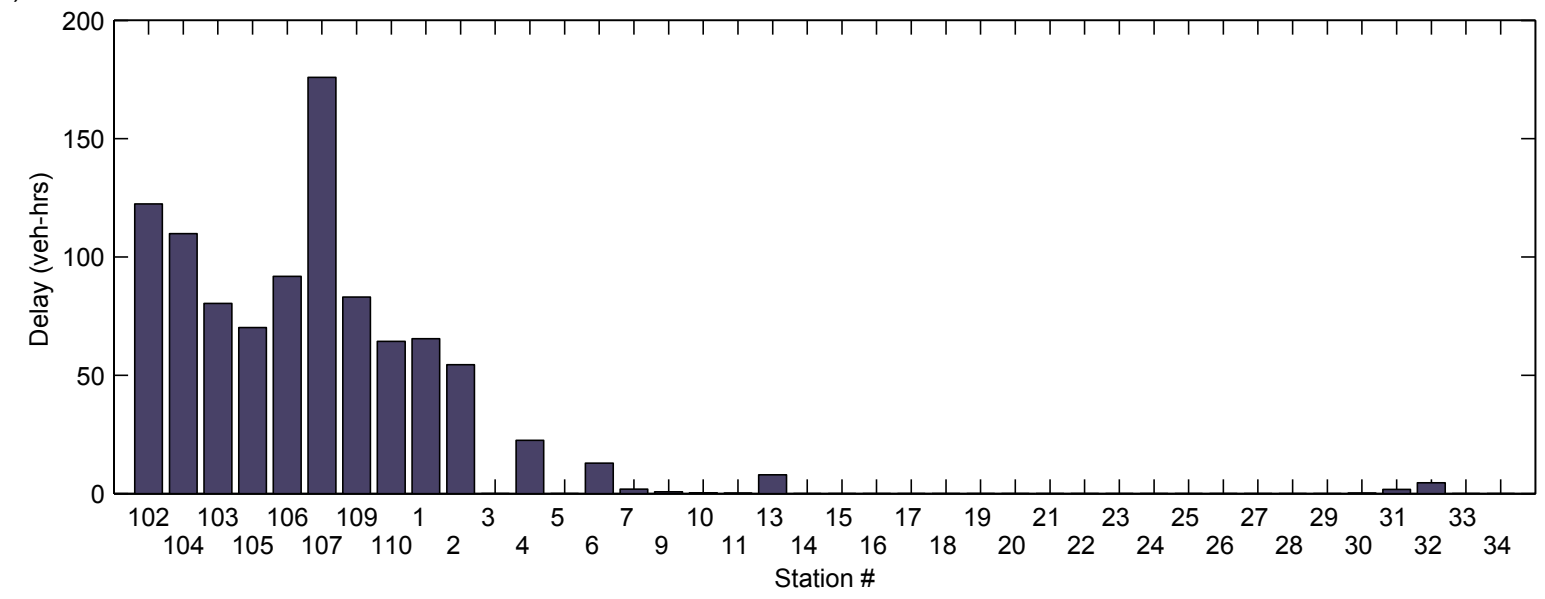

B)

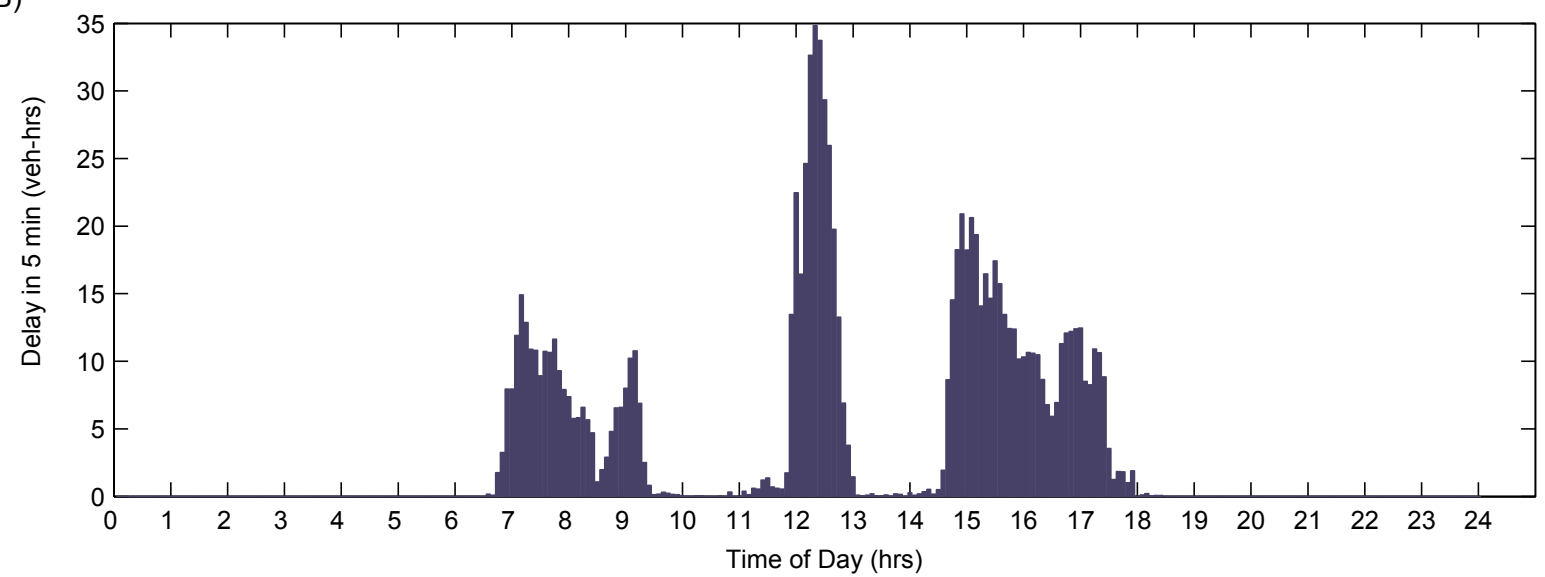

Figure 28, The total delay corresponding to Figure 26A is 971 veh-hrs, (A) shown by detector station sorted by increasing distance (from Figure 26), (B) shown by time of day, note the peak around noon due to an incident. 


\section{Other Measures}

Many metrics are well suited to time series presentation (speed, flow, occupancy, travel time, delay, etc.), e.g., Figure 26. Other measures are well suited to averaging over time and space (vehicle miles traveled (VMT), delay, amount of time delay is present, etc.), e.g., Figure 10 and 27 , or deviations from typical conditions, e.g., Figure 12. For some of the metrics it makes sense to aggregate by day in addition to other time periods (VMT, delay, amount of time delay is present, and average daily travel (ADT)). When examining time series of these daily values over an extended period, it quickly becomes difficult to pull out meaningful trends in the presence of typical daily variability (e.g., incidents or holidays). To overcome this problem we take the median of the weekday values for each week. One could easily use min, max or another statistic; restrict the analysis to a specific day of the week, or so forth. This process of taking the median weekday allows one to review several years of data on a single plot and still extract useful information. For example, Figures 29-32 show the median weekday ADT and delay at 8 directional stations for three years, almost the entire period for which the CMFMS has collected data. In all of these plots, the chevron on the map to the right of the plots shows the direction and approximate location of the given detector station. Of course if a detector goes down in one or more lanes, the measures may no longer be valid. A simple procedure is employed if no data were recorded over a day from a loop that is expected to be operational it is marked as being non-operational. The measures from the affected station are presented during these periods because they may still hold meaning, however, they are shown with a different line style (dashed lines in a different color for this report) to allow a user to easily identify such periods.

The impacts of many of the major events enumerated earlier are evident in the plots. For example, I670 offered an alternative route for traffic on the southern portion of the instrumented corridor. The plots show the period that $\mathrm{I} 670$ was closed for complete reconstruction. Both ADT and delay increased significantly on the parallel portion of the I71 corridor, e.g., Figure 29 for northbound traffic. The impact on ADT is much smaller north of the junction of the two routs, e.g., Figure 30. However, the increased flow from I670 has caused a bottleneck on I71, within a mile of the junction, to become active (compare the delay at the two locations in Figure 30). On the other hand, Figure 31 suggests that delay was alleviated around the I71/I670 junction, but increased at the southern end of the corridor, perhaps due to queues backing up from the I70/I670 junction. 

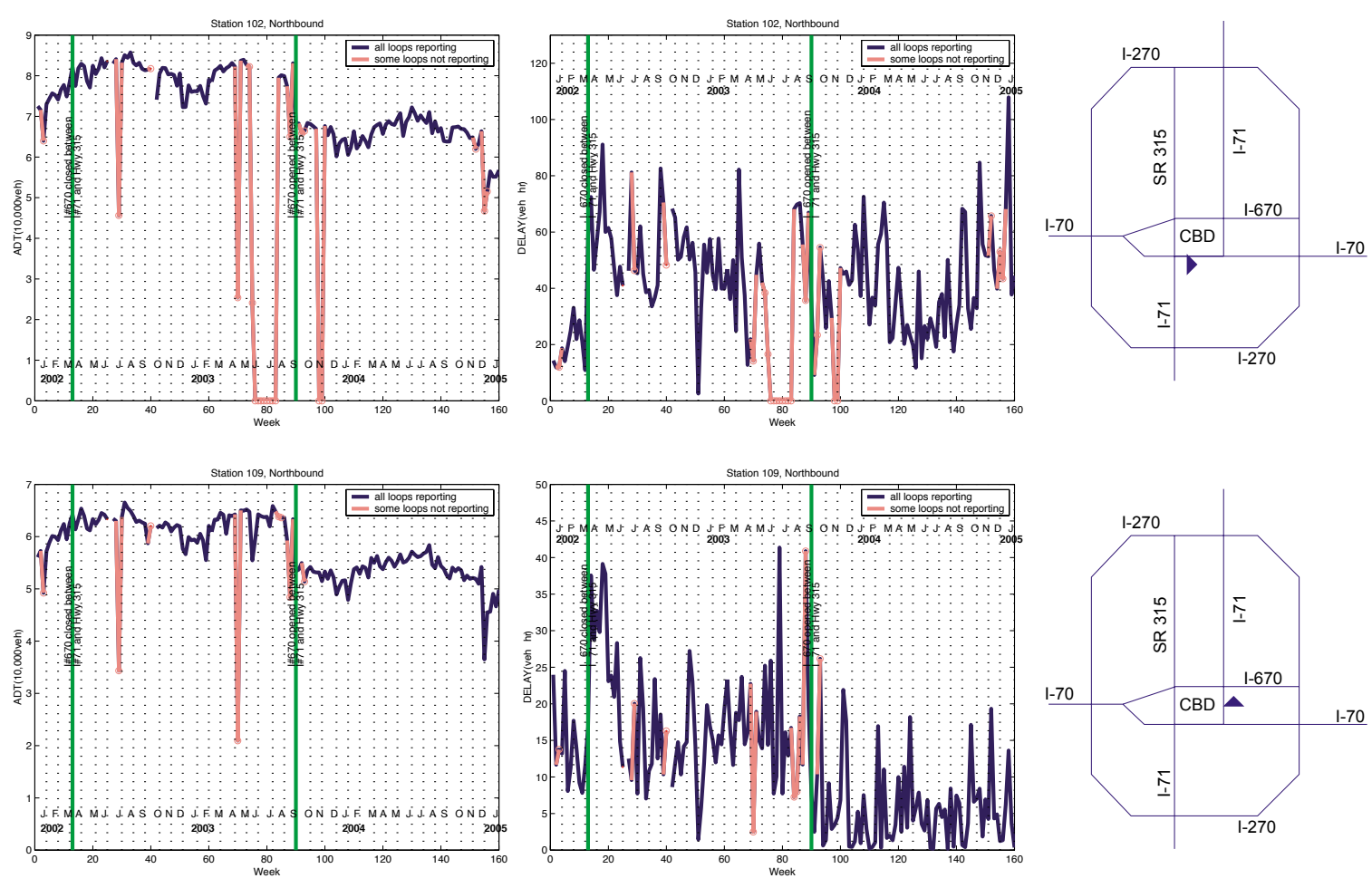

Figure 29, Northbound weekly median daily ADT and delay for the two detector stations shown on the right over three years.
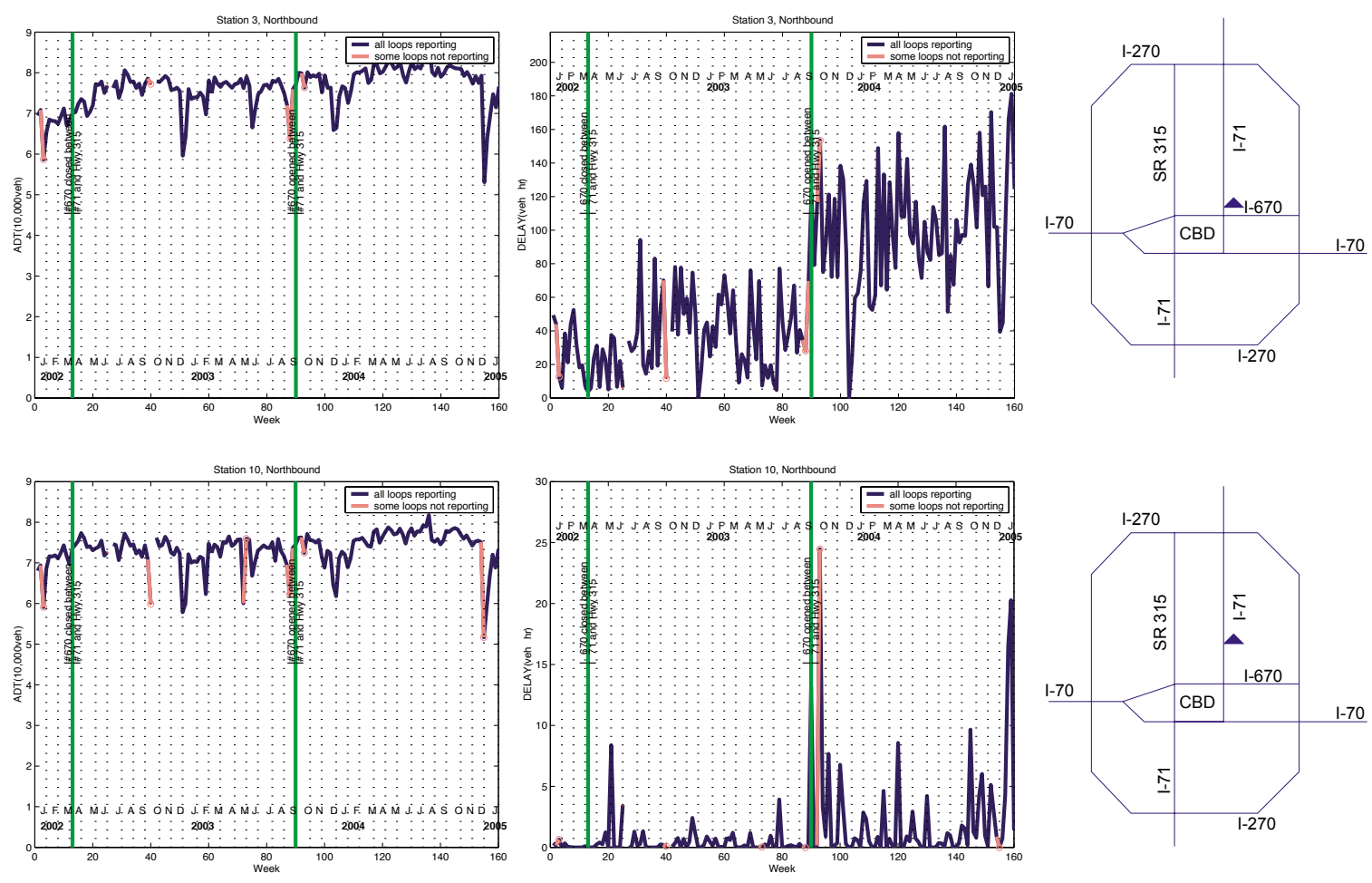

Figure 30, Northbound weekly median daily ADT and delay for the two detector stations shown on the right over three years. 

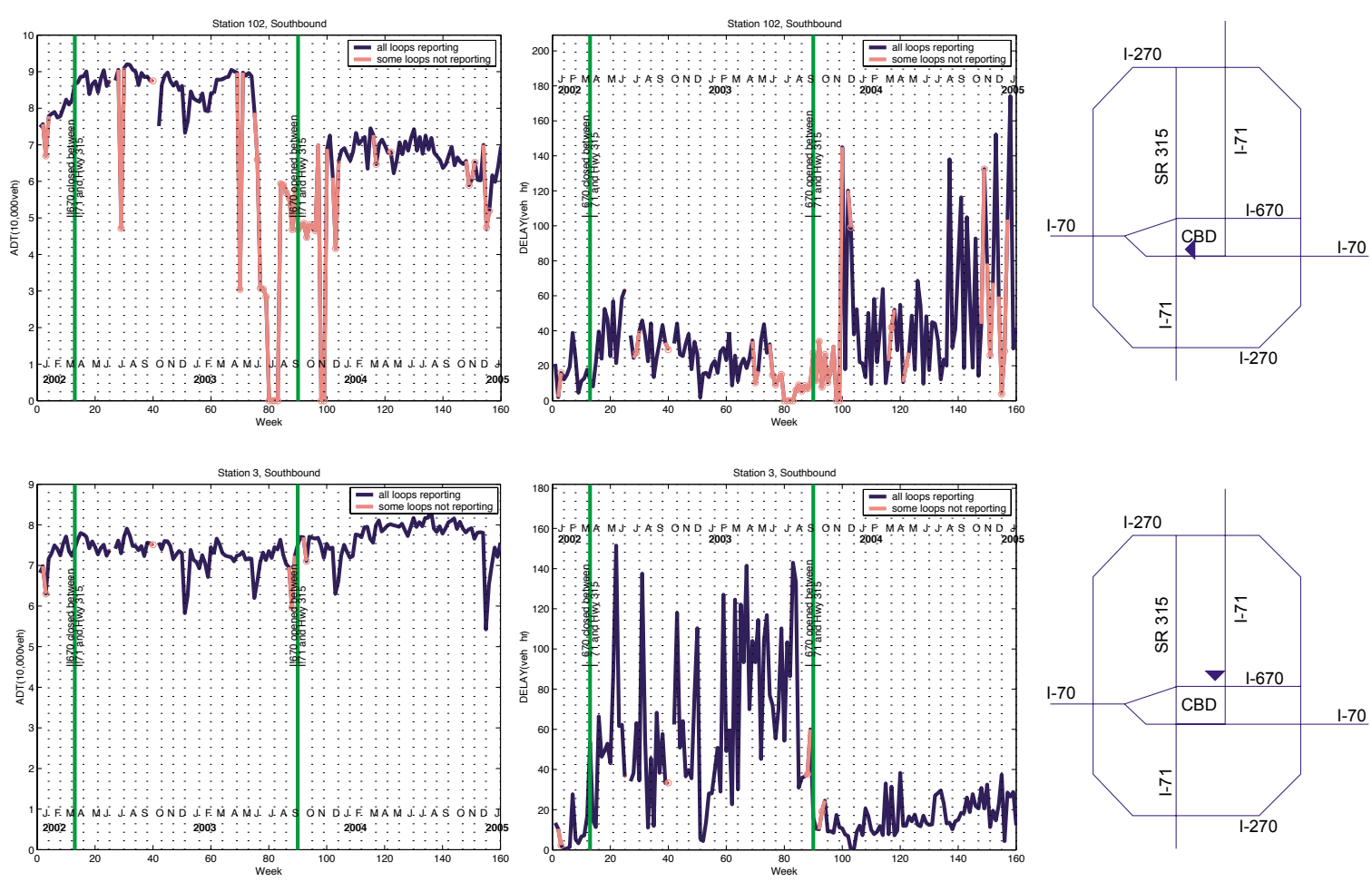

Figure 31, Southbound weekly median daily ADT and delay for the two detector stations shown on the right over three years.
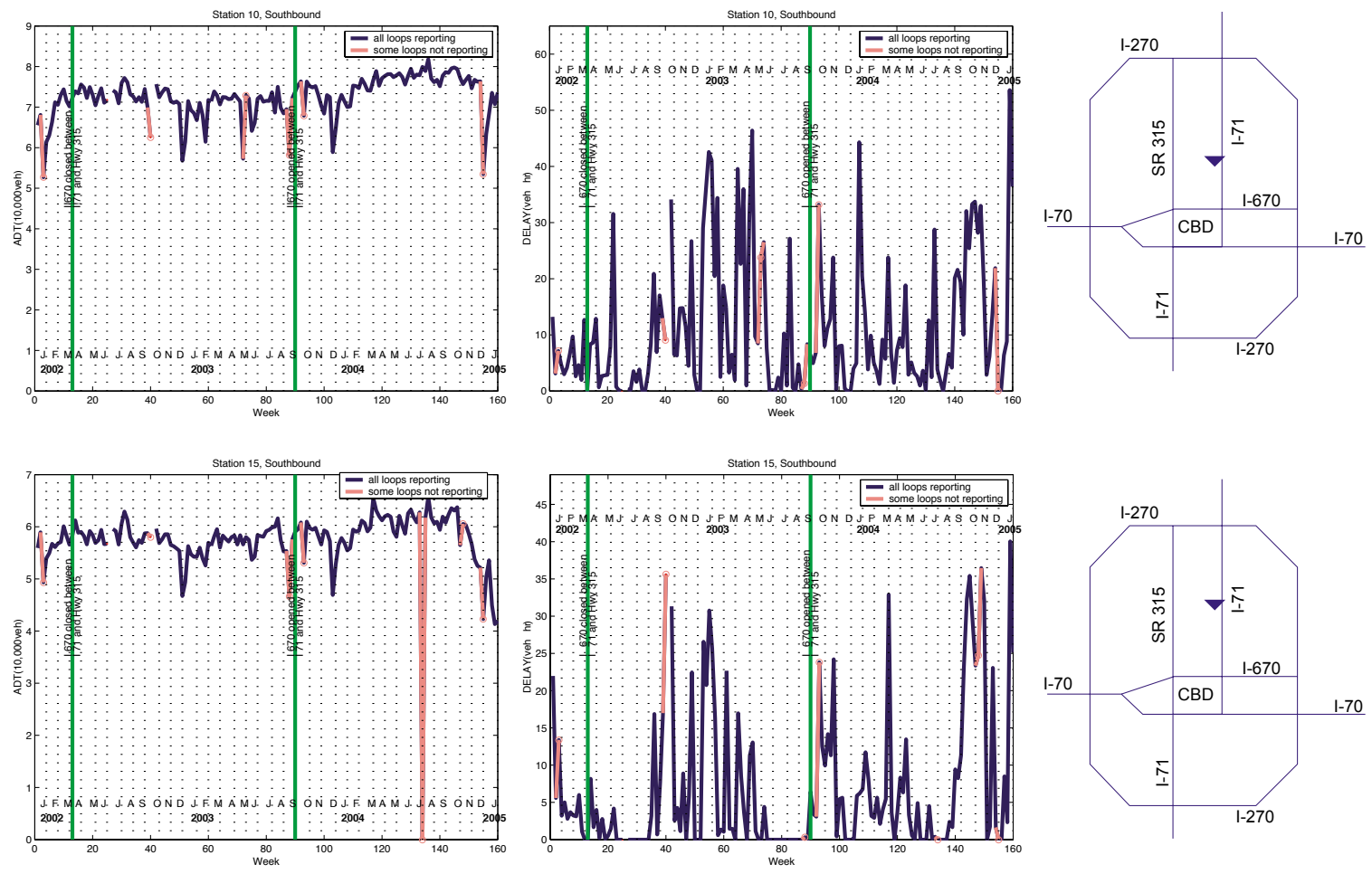

Figure 32, Southbound weekly median daily ADT and delay for the two detector stations shown on the right over three years. 


\section{Closing ANd Conclusions}

This research examined the value of information collected over time from a conventional traffic monitoring system deployed for real time control. Most major cities in the US have either deployed a real time control system or are in the design phase of such a system. The focus on real time control neglects the benefits of assessing the performance of the system over time. As noted in the review of on-line traveler information systems, a couple have begun to address this omission, e.g., [1, 19], but there is still much more to be done before such ideas are embraced by standard practice.

We use the CMFMS for the data source strictly out of convenience, the concepts examined by the research are generalizable to most existing and planned traffic monitoring systems. The largest cost for traffic monitoring is the detectors and communication. In relative terms, the cost processing and post-processing incoming data is a very small. At the low end, an off-line analysis tool could cost less than $\$ 5,000$ in hardware and software (one PC with sufficient storage for the data and a data analysis package such as Matlab). Yet as laid out in this report, provided care is used to highlight features of interest, the resulting information could prove highly beneficial, yielding new insights on the operation of the road network and possibly reducing the need for separate detectors for measuring ADT for planning applications.

As laid out in this report, we first examined the performance of the detectors to validate that they are operating correctly, this calibration task would be necessary for any traffic monitoring system. The specific means of calibration, e.g., probe vehicle or radar detector, is not nearly as important as carefully making sure the data are time synchronized in the comparison. After this calibration, we developed many different ways to graphically mine historical data from the real time system. One of the fundamental tools is our so-called summary plot, showing the evolution of speed over time and space. This plot shows queues growing and shrinking in response both to recurring and non-recurring congestion. It also shows many system failures that prevent data measurement at one or more stations. Taking the difference between a specific day and some average of several days can highlight non-recurring events. In either case, once comfortable with these plots, one can easily review conditions from an entire month on a single sheet of paper.

Related to the summary plots and the underlying speed data, the research also examined several measures to capture travel time conditions experienced by travelers. After validation, these data were used to illustrate several different means of presentation, including statistical measures throughout the "typical day" and curves of equi-travel time. Once one can measure travel time it is a simple task to measure and quantify delay. Naturally, care must be taken to ensure that any speeding vehicles or detector errors do not result in negative delay.

Several measures were examined such as delay, ADT, VMT and hours a given station was congested, all of which can be expressed as a daily measure per station, temporal measure across all stations, or simply a daily measure across many stations. Ordinarily one would expect to see variation from day to day as well as a difference between weekday and weekend conditions. This variability makes it difficult to interpret a plot of time series data more than a few weeks long. To address this problem, we used the conceptually simple weekly-median filter to clearly show conditions from each week over three years. Once more, care must be taken to 
differentiate between changes due to detectors being down and changes due to travel patterns, as was done in the body of this work. Finally, a prototype illustrating many of these features was deployed in real time at [2]. 


\section{REFERENCES}

[1] http://pems.eecs.berkeley.edu

[2] http://tml.ece.ohio-state.edu/CMFMS

[3] Coifman, B. "Using Dual Loop Speed Traps to Identify Detector Errors", Transportation Research Record 1683, Transportation Research Board, 1999, pp 47-58.

[4] Coifman, B., Dhoorjaty, S., "Event Data Based Traffic Detector Validation Tests", ASCE Journal of Transportation Engineering, Vol 130, No 3, 2004, pp 313-321.

[5] http://www.wsdot.wa.gov/traffic/seattle/

[6] http://www.gemtravel.com

[7] http://www.dot.wisconsin.gov/travel/milwaukee/

[8] http://511.org/

[9] http://traffic.houstontranstar.org

[10] http://www.az511.com/

[11] http://www.mto.gov.on.ca/english/traveller/compass/

[12] http://www.tripcheck.com/RoadCond/izone16.htm

[13] http://traffic.com

[14] http://traffic.iteris.com/

[15] http://scripts.ci.columbus.oh.us/trafficcam/

[16] http://www.dot.state.oh.us/i-670/cameras.asp

[17] http://www.wsdot.wa.gov/traffic/seattle/traveltimes/reliability/

[18] http://raffic.houstontranstar.org/speedcharts/

[19] http://traffic.houstontranstar.org/hist/historydata.html

[20] http://trafficdataarchive.ce.virginia.edu

[21] http://www.its.washington.edu/tdad/

[22] http://portal.its.pdx.edu/

[23] Coifman, B., Dhoorjaty, S., Lee, Z. "Estimating Median Velocity Instead of Mean Velocity at Single Loop Detectors", Transportation Research: Part C, vol 11, no 3-4, 2003, pp 211-222.

[24] Jain, M., Coifman, B., "Improved Speed Estimates from Freeway Traffic Detectors" ASCE Journal of Transportation Engineering, (forthcoming).

[25] Coifman, B. "Estimating Travel Times and Vehicle Trajectories on Freeways Using Dual Loop Detectors", Transportation Research: Part A, vol 36, no 4, 2002, pp. 351-364.

[26] Coifman, B., Cassidy, M. "Vehicle Reidentification and Travel Time Measurement on Congested Freeways", Transportation Research: Part A, vol 36, no 10, 2002, pp. 899-917.

[27] Coifman, B. "Identifying the Onset of Congestion Rapidly with Existing Traffic Detectors", Transportation Research: Part A, vol 37, no 3, 2003, pp. 277-291. 